This item was submitted to Loughborough's Research Repository by the author.

Items in Figshare are protected by copyright, with all rights reserved, unless otherwise indicated.

\title{
Hydrophilic MacroRAFT-mediated emulsion polymerization: Synthesis of latexes for cross-linked and surfactant-free films
}

PLEASE CITE THE PUBLISHED VERSION

https://doi.org/10.1021/acs.macromol.7b01885

\section{PUBLISHER}

(c) American Chemical Society (ACS)

\section{VERSION}

AM (Accepted Manuscript)

\section{PUBLISHER STATEMENT}

This work is made available according to the conditions of the Creative Commons Attribution-NonCommercialNoDerivatives 4.0 International (CC BY-NC-ND 4.0) licence. Full details of this licence are available at: https://creativecommons.org/licenses/by-nc-nd/4.0/

\section{LICENCE}

CC BY-NC-ND 4.0

\section{REPOSITORY RECORD}

de la Haye, Jennifer Lesage, Ignacio Martin-Fabiani, Malin Schulz, Joseph L. Keddie, Franck D'Agosto, and Muriel Lansalot. 2018. "Hydrophilic Macroraft-mediated Emulsion Polymerization: Synthesis of Latexes for Cross-linked and Surfactant-free Films”. figshare. https://hdl.handle.net/2134/28048. 


\section{Hydrophilic MacroRAFT-Mediated Emulsion Polymerization: Synthesis of Latexes for}

\section{Crosslinked and Surfactant-Free Films}

Jennifer Lesage de la Haye, ${ }^{1}$ Ignacio Martin-Fabiani, ${ }^{2}$ Malin Schulz, ${ }^{3}$ Joseph L. Keddie,,$^{*}$ Franck D’Agosto, ${ }^{1^{*}}$ Muriel Lansalot ${ }^{{ }^{*}}$

${ }^{1}$ Univ Lyon, Université Claude Bernard Lyon 1, CPE Lyon, CNRS, UMR 5265, Chemistry, Catalysis, Polymers \& Processes (C2P2), 43 Bd du 11 Novembre 1918, 69616 Villeurbanne, France.

${ }^{2}$ Department of Materials, Loughborough University, Loughborough, Leicestershire LE11 3TU, United Kingdom.

${ }^{3}$ Department of Physics, University of Surrey, Guildford, Surrey GU2 7XH, United Kingdom.

\section{Abstract}

A major drawback of conventional emulsion polymers arises from the presence of migrating low molecular weight surfactants that contribute to poor water barrier properties and low adhesion to substrates. In this paper, we demonstrate how living polymer chains obtained by reversible addition-fragmentation chain transfer (RAFT) can be used as an efficient stabilizer in emulsion polymerization, leading to the production of surfactant-free latexes, which then form crosslinked films with beneficial properties. Hydrophilic poly(methacrylic acid) (PMAA) chains obtained by RAFT performed in water are used to mediate emulsion polymerization and produce film-forming latex particles from mixtures of methyl 
methacrylate, $n$-butyl acrylate and styrene. Stable dispersions of particles with sizes between 100 and $200 \mathrm{~nm}$ are obtained, with very low amounts of coagulum (< $0.5 \mathrm{wt} . \%)$. The particles are stabilized by the PMAA segment of amphiphilic block copolymers formed during the polymerization. Remarkably, low amounts of PMAA chains (from 1.5 wt.\% down to 0.75 wt.\%) are enough to ensure particle stabilization. Only traces of residual PMAA macroRAFT agents are detected in the final latexes, showing that most of them are successfully chain extended and anchored on the particle surface. The $T_{g}$ of the final material is adjusted by the composition of the hydrophobic monomer mixture so that film formation occurs at room temperature. Conventional crosslinking strategies using additional hydrophobic comonomers, such as 1,3-butanediol diacrylate (BuDA), diacetone acrylamide (DAAm), and (2acetoacetoxy)ethyl methacrylate, are successfully applied to these formulations as attested by gel fractions of $100 \%$. When particles are internally crosslinked with BuDA, chain interdiffusion between particles is restricted, and a weak and brittle film is formed. In contrast, when DAAm undergoes crosslinking during film formation, full coalescence is achieved along with the creation of a crosslinked network. The resulting film has a higher Young's modulus and tensile strength as a result of crosslinking. This synthetic strategy advantageously yields a surfactant-free latex that can be formed into a film at room temperature with mechanical properties that can be tuned via the crosslinking density.

Keywords: RAFT, emulsion polymerization, PISA, surfactant-free, latex film formation, crosslinking 


\section{Introduction}

For more than two decades, manufacturers of coatings, adhesives and inks have responded to environmental legislation restricting the emission of volatile organic compounds (VOC), ${ }^{1}$ which has driven the development of environmentally-friendly waterborne polymers. At the same time, the demand for higher solids dispersions (e.g. for coatings applications) has markedly increased to make savings in transport costs. In waterborne polymer systems, the stability of the final product is conventionally ensured by the use of low molar mass ingredients, such as surfactants (Scheme 1a). However, when emulsion polymers undergo film formation, their hydrophilic species are prone to migration ${ }^{2}$ and segregation at film interfaces, which has detrimental effects on properties such as gloss, ${ }^{3}$ water sorption and permeability, ${ }^{4}$ and adhesion to a substrate. The design of surfactant-free latexes, performing as well as their surfactant-containing analogues, has therefore been a target for both academia and industry for more than twenty years..$^{5-11}$

In the specific field of emulsion polymerization in water, different strategies have been employed, most of them relying on the use of hydrophilic (macro)molecules able to participate in one of the key steps (initiation, propagation, termination) of the free radical polymerization process. The resulting species are trapped at the surface of the particles ensuring the stability via their hydrophilic moiety.

This approach is indeed part of the concept of the so-called polymerization-induced selfassembly (PISA) strategy ${ }^{12-15}$ that takes advantage of the chain end reactivity of solvophilic macromolecules obtained by reversible-deactivation radical polymerization (RDRP) for the polymerization of solvophobic monomers. Involved either in a reversible termination reaction (such as in nitroxide mediated polymerization ${ }^{16}$ ) or in a reversible transfer reaction (such as in reversible addition-fragmentation chain transfer $(\mathrm{RAFT})^{17}$ or organotellerium-mediated radical polymerization ${ }^{18}$ ), hydrosoluble chains can thus be extended with a hydrophobic 
monomer in water. The amphiphilic block copolymers produced in situ are then excellent stabilizers for the particles prepared by emulsion polymerization (see Scheme 1c). When the growth of the hydrophobic segment is perfectly controlled from all the water-soluble chains, the resulting particles are exclusively composed of amphiphilic block copolymers that selfassemble upon the growth of the hydrophobic segment to form nano-objects that can feature different morphologies whether they are prepared by aqueous dispersion ${ }^{19-20}$ or emulsion $^{21-24}$ polymerization. Recently, hard and soft blocks in PISA-assembled nanoparticles have been designed to create percolating nanostructures in films ${ }^{25}$ and to combine high stiffness with extensibility. ${ }^{26}$ Self-assembled nanofibers have been successfully used as reinforcing fillers for waterborne acrylic films. ${ }^{27}$ Block copolymer particles obtained by PISA, however, do not lead to the conventional latex particles used in colloidal film applications and that incorporate high molar mass polymers. In addition, the amount of reactive water-soluble macromolecules employed (usually > 5 wt.\% compared to the hydrophobic monomer) is not compatible with the low amount of hydrophilic species required in the final coating for the formation of waterresistant films particularly targeted toward paint technology.

Considering the restrictions on the use of low molar mass surfactants and the target of high solids dispersions, an interesting approach to produce high solids surfactant-free latexes is to use the minimum amount of living hydrophilic chains to produce enough amphiphilic block copolymers. These chains can further act as efficient stabilizers for the film-forming polymer particles produced simultaneously. In this approach, the control on the growth of the hydrophobic chains in the particle core is not sought (Scheme 1b). So far, little attention has been paid to produce such industrially-relevant and potentially industrially-competitive colloidal formulations. Instead, the vast majority of the literature published in this area investigates the design of amphiphilic block copolymer particles and the corresponding morphology, ${ }^{13-15}$ or the use of preformed amphiphilic block copolymers as surfactants. ${ }^{28-32}$ 
We, however, recently demonstrated that industrially relevant poly(vinyl chloride-co-methyl acrylate) latex particles (40 wt.\% solids) incorporating less than 2 wt.\% of hydrophilic poly(acrylic acid) (PAA), poly(methacrylic acid) (PMAA), or poly(sodium styrene sulfonate) (PSSNa) synthesized by RAFT could be produced using this strategy and ultimately form transparent films. ${ }^{33}$

a)

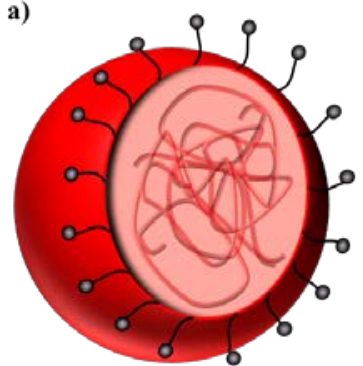

- Particles stabilized by low molar mass surfactant

- No control over the molar mass of the chains in the particle core b)

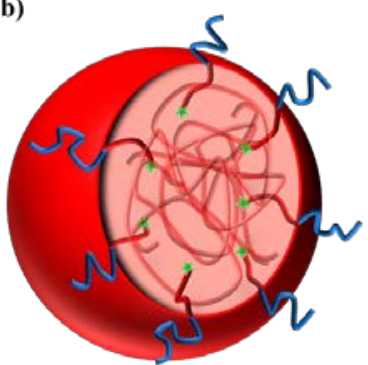

- Particles stabilized by amphiphilic copolymers

- No control over the molar mass of the chains in the particle core

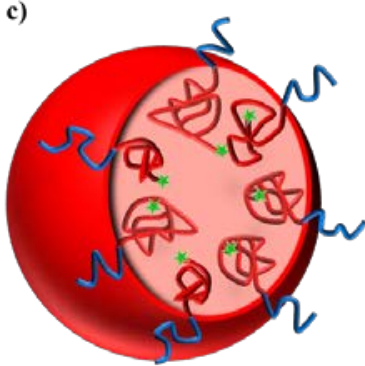

- Particles stabilized and composed of amphiphilic copolymers

Legend: $\quad \underbrace{0}$ Low molar mass surfactant

Hydrophobic polymer chain

Amphiphilic living chain

Scheme 1. Structure of polymer particles obtained from batch emulsion polymerization performed in the presence of a) a low molar mass surfactant, b) a low concentration of hydrophilic living chains (typically $\leq 2$ wt.\%) and c) a high concentration of hydrophilic living chains ( $\geq 2$ wt.\%).

The present paper describes the successful implementation of this strategy using watersoluble PMAA obtained by RAFT for the production of surfactant-free film-forming latex particles composed of methyl methacrylate (MMA), $n$-butyl acrylate (BA) and styrene (S), in a one-pot/two-step process exclusively conducted in water. Our first efforts were directed towards the synthesis of non-crosslinking polymers. We have then modified the formulations to produce film-forming latexes that can be crosslinked during or after film formation.

Crosslinking of polymers to create a three-dimensional network is an established method to tailor their properties. The crosslinking of thermoplastic polymers increases their elastic 
modulus, prevents dissolution in good solvents, and inhibits long-range chain diffusion. ${ }^{34}$

During the latex film formation process, polymer particles in water are cast on a substrate. When the water evaporates, the particles pack closely together and then deform from their spherical shape. To achieve mechanical strength, the individual molecules in the particles must diffuse across the particle boundaries to form chain entanglements across the interface. Densely crosslinked chains are not able to entangle across particle interfaces, and hence they yield weak or brittle films. ${ }^{35}$

In some latex systems, crosslinking takes place during the film formation process. ${ }^{36}$ In order to achieve cohesion in crosslinking latex films, the interdiffusion process must occur prior to the polymer chains being locked in a crosslinked network. ${ }^{37}$ If the rate of interdiffusion is slow relative to the crosslinking rate, chain entanglements are not formed at the particle interfaces, and a weak or brittle film will result. Models ${ }^{38}$ and experiments ${ }^{34,39}$ have both supported these concepts. In this work, we compare the properties of films cast from crosslinked latex particles to those of films that crosslink during film formation.

To the best of our knowledge this work is the first one depicting the combined use of macroRAFT-mediated emulsion polymerization and crosslinking chemistry for the formation of cohesive crosslinked films with tuneable mechanical properties.

\section{Experimental section}

\section{Materials.}

n-Butyl acrylate (BA, Acros, 99\%), methyl methacrylate (MMA, Acros, 99\%), styrene (S, Acros, 99\%), methacrylic acid (MAA, Acros, 99.5\%), 1,3-butanediol diacrylate (BuDA, Aldrich, 98\%), diacetone acrylamide (DAAm, Aldrich, 99\%), (2-acetoacetoxy)ethyl methacrylate (AAEM, Aldrich, 95\%), ammonium persulfate (APS, Acros Organics, 98\%), 
adipic acid dihydrazide (ADH, Aldrich, $\geq 98 \%$ ), hexamethylenediamine (HMDA, Aldrich, 98\%) and 4,4-azobis(4-cyanopentanoic acid) (ACPA, Aldrich, > 98\%) were used as received. Water was deionized before use (Purelab Classic UV, Elga LabWater). 4-Cyano-4thiothiopropylsulfanylpentanoic acid (CTPPA) was obtained by reaction of ACPA with bis(propylsulfanylthiocarbonyl) disulfide as described in the literature. ${ }^{40-41}$

\section{Synthesis of PMAA macroRAFT agents in water.}

$\mathrm{PMAA}_{2 \mathrm{k}}$ and $\mathrm{PMAA}_{4 \mathrm{k}}$ macroRAFT agents (with respectively targeted number-average molar masses $M_{\mathrm{n}}$ of ca. $2000 \mathrm{~g} \mathrm{~mol}^{-1}$ or $4000 \mathrm{~g} \mathrm{~mol}^{-1}$ ) were obtained in water using CTPPA as a chain transfer agent and ACPA as a radical initiator. ${ }^{42-43}$ In a typical experiment (PMAA $2 \mathrm{k}$ ), ACPA (16.6 mg, $\left.5.80 \times 10^{-5} \mathrm{~mol}\right)$, CTPPA (160.0 mg, $\left.5.77 \times 10^{-4} \mathrm{~mol}\right)$, and MAA $(1.0 \mathrm{~g}$, $\left.1.16 \times 10^{-2} \mathrm{~mol}\right)$ were dissolved in water $(10.6 \mathrm{~mL})$ in a round-bottom flask. 1,3,5-trioxane (174.5 mg, $1.93 \times 10^{-3} \mathrm{~mol}$ ) was added as an internal reference for NMR analysis (see Supporting Information). After deoxygenation by argon bubbling for $30 \mathrm{~min}$, the resulting mixture was immersed in an oil bath thermostated at $80{ }^{\circ} \mathrm{C}$, which corresponded to time zero of the polymerization. After $5 \mathrm{~h}$, the polymerization was stopped by immersion of the flask in ice and opening to air. This PMAA $2 \mathrm{k}\left(M_{\mathrm{n}, \mathrm{th}}=1991 \mathrm{~g} \mathrm{~mol}^{-1}, M_{\mathrm{n}, \exp }=2142 \mathrm{~g} \mathrm{~mol}^{-1}, Ð=1.19\right)$ was used without further purification in the following emulsion step. The same procedure was followed for the synthesis of PMAA4k $\left(M_{\mathrm{n}}=3840 \mathrm{~g} \mathrm{~mol}^{-1}, \oslash=1.23\right)$.

\section{Surfactant-free latexes stabilized with PMAA macroRAFT agent}

Different emulsion copolymerizations of BA/MMA or BA/MMA/styrene were performed in the presence of $\mathrm{PMAA}_{2 \mathrm{k}}$ and PMAA $4 \mathrm{k}$ macroRAFT agents. All the experiments were performed at $70{ }^{\circ} \mathrm{C}$ in a $250 \mathrm{~mL}$ double-jacket glass reactor equipped with a condenser. In a typical experiment (Latex 3 in Table 1$)$, APS $\left(27.1 \mathrm{mg}, 7.09 \times 10^{-3} \mathrm{~mol}\right)$ was added to a solution of previously synthesized $\mathrm{PMAA}_{2 \mathrm{k}}(8.0 \mathrm{wt} . \%$ aqueous solution, $1.0 \mathrm{wt} . \%$ of PMAA $2 \mathrm{k}$ based on monomers (bom)). Water content was adjusted to target a final solids content $(\tau)$ of 
40 wt. $\%$, with $\tau=\left(\mathrm{m}_{0-\mathrm{M}}+\mathrm{m}_{0 \text {-PMAA2K }}\right) / \mathrm{m}_{0 \text {-total }}$ where $\mathrm{m}_{0-\mathrm{M}}$ is the initial mass of the hydrophobic monomers and $m_{0 \text {-total }}$ is the total mass of the polymerization mixture introduced in the reactor. The $\mathrm{pH}$ of this solution was adjusted to 7 with a $1 \mathrm{~mol} \mathrm{~L}{ }^{-1} \mathrm{NaOH}$ aqueous solution. BA (24.0 g, $\left.1.87 \times 10^{-1} \mathrm{~mol}, 60 \mathrm{wt} . \% \mathrm{bom}\right)$ and MMA $\left(16.0 \mathrm{~g}, 1.60 \times 10^{-1} \mathrm{~mol}\right.$, 40 wt.\% bom) were added. The resulting mixture was deoxygenated by purging with nitrogen for $30 \mathrm{~min}$, and then introduced into the reactor set at $70{ }^{\circ} \mathrm{C}$. The polymerization was stopped after $5 \mathrm{~h}$ of stirring at $330 \mathrm{rpm}$. Monomer consumption was followed by gravimetric analysis of samples withdrawn from the polymerization medium at different times. The recipes of the different polymerizations and the characteristics of the corresponding latexes are given in Table 1.

Table 1. Surfactant-free latexes stabilized with PMAA macroRAFT agents

\begin{tabular}{|c|c|c|c|c|c|c|c|c|c|c|}
\hline Latex & Monomers $^{a}$ & $\begin{array}{c}\text { wt. } \%^{\circ} \\
\text { PMAA }^{b}\end{array}$ & t (h) & $\begin{array}{c}\text { Conv }^{c} \\
(\%)\end{array}$ & $\begin{array}{c}\tau^{d} \\
(w t . \%)\end{array}$ & $\begin{array}{l}\text { Coag }^{e} \\
\text { (wt. \%) }\end{array}$ & $\begin{array}{c}D_{\mathrm{z}}(\mathrm{nm}) / \\
\text { PDI }^{f}\end{array}$ & $\mathrm{pH}_{\mathrm{f}}{ }^{g}$ & $\begin{array}{l}T_{\mathrm{g}} h \\
\left({ }^{\circ} \mathrm{C}\right)\end{array}$ & $\begin{array}{c}\text { MFFT }^{i} \\
\left({ }^{\circ} \mathrm{C}\right)\end{array}$ \\
\hline 1 & $\begin{array}{c}\text { BA/MMA } \\
(55 / 45)\end{array}$ & 1.5 & 5.2 & 96 & 39.7 & 0.50 & $214 / 0.02$ & - & n.d. & n.d. \\
\hline 2 & $\begin{array}{c}\text { BA/MMA } \\
(60 / 40)\end{array}$ & 1.5 & 4.0 & 100 & 40.6 & 0.10 & 149 / 0.02 & 7.1 & $\begin{array}{l}-23.6 / \\
+13.9\end{array}$ & 5 \\
\hline 3 & $\begin{array}{c}\text { BA/MMA } \\
(60 / 40)\end{array}$ & 1.0 & 5.0 & 100 & 40.4 & 0.19 & $196 / 0.02$ & 7.5 & $\begin{array}{l}-26.4 / \\
+17.9\end{array}$ & 2 \\
\hline $4^{j}$ & $\begin{array}{c}\text { BA/MMA } \\
(60 / 40)\end{array}$ & 1.0 & 6.5 & 97 & 40.0 & 0.49 & $126 / 0.04$ & 7.0 & -1.1 & n.d. \\
\hline 5 & $\begin{array}{c}\text { BA/S } \\
(55 / 45)\end{array}$ & 1.0 & 6.2 & 100 & 40.2 & 0.01 & 89 / 0.04 & - & n.d. & n.d. \\
\hline 6 & $\begin{array}{c}\text { BA/S } \\
(55 / 45)\end{array}$ & 0.75 & 5.8 & 95 & 40.2 & 0.08 & 90 / 0.02 & 6.8 & +16.8 & n.d. \\
\hline 7 & $\begin{array}{c}\text { BA/S/MMA } \\
(60 / 25 / 15)\end{array}$ & 0.75 & 6.2 & 93 & 40.2 & 0.20 & $117 / 0.03$ & - & +6.0 & n.d. \\
\hline 8 & $\begin{array}{c}\text { BA/S/MMA } \\
(60 / 15 / 25)\end{array}$ & 0.75 & 6.5 & 96 & 40.2 & 0.47 & 152 / 0.01 & - & n.d. & n.d. \\
\hline 9 & $\begin{array}{c}\text { BA/S/MMA } \\
(60 / 15 / 25)\end{array}$ & 1.0 & 6.5 & 100 & 40.5 & 0.35 & $128 / 0.10$ & - & n.d. & n.d. \\
\hline 10 & $\begin{array}{c}\text { BA/S/MMA } \\
(60 / 15 / 25)\end{array}$ & 1.5 & 5.0 & 100 & 40.5 & 0.08 & $96 / 0.02$ & 7.2 & $-k$ & 2 \\
\hline 11 & $\begin{array}{c}\text { BA/S/MMA } \\
(60 / 10 / 30)\end{array}$ & 1.0 & 6.3 & 100 & 40.4 & 0.44 & $128 / 0.02$ & - & n.d. & n.d. \\
\hline 12 & $\begin{array}{c}\text { BA/S/MMA } \\
(60 / 10 / 30)\end{array}$ & 1.5 & 5.0 & 100 & 40.5 & 0.13 & $107 / 0.02$ & 7.2 & $-k$ & 2 \\
\hline
\end{tabular}

All the experiments were performed at $70{ }^{\circ} \mathrm{C}$, using $2 \mathrm{mmol} \mathrm{L}^{-1}$ water of APS. The pH was initially adjusted to 7 by addition of a $1 \mathrm{M} \mathrm{NaOH}$ 
solution. ${ }^{a}$ Composition of the initial mixture of hydrophobic monomers. Weight fractions are given in brackets. ${ }^{b}$ With respect to the monomers. The reactions were all carried out with PMAA $_{2 \mathrm{k}}$, except for Latex 1 where PMAA $4 \mathrm{k}$ was used. ${ }^{c}$ Determined by gravimetry. ${ }^{d}$ Solids content $\tau(\%)=\left(\mathrm{m}_{0-\mathrm{M}}+\mathrm{m}_{0 \text {-macroRAFT }}\right) / \mathrm{m}_{0 \text {-total }}{ }^{e}$ On the basis of the total latex mass. ${ }^{f} D_{\mathrm{z}}$ is the z-average particle diameter and PDI the dispersity factor determined by dynamic light scattering. ${ }^{g}$ Final $\mathrm{pH}$ of the latex. ${ }^{h} \mathrm{~T}_{\mathrm{g}}$ measured at the midpoint, at $20{ }^{\circ} \mathrm{C}$ min ${ }^{-1}$. ${ }^{i} \mathrm{Measured}$ according to ASTM D2354 using a MFFT bar-90 equipment. ${ }^{j}$ Semi-batch experiment: The reactor was first filled with the aqueous PMAA macroRAFT solution and APS, adjusted at $\mathrm{pH}$ 7. The temperature was set to $70{ }^{\circ} \mathrm{C}$ The monomer mixture was then fed at $10 \mathrm{~mL} \mathrm{~h}^{-1}$, over 4 h. The polymerization was stopped $2.5 \mathrm{~h}$ after the end of the monomer mixture addition. ${ }^{k}$ Very broad $T_{\mathrm{g}}$. n.d.: not determined.

\section{Surfactant-free (self)-crosslinking latexes stabilized with PMAA2k macroRAFT agent}

PMAA $_{2 \mathrm{k}}$ macroRAFT agent was synthesized as described above and used in the following without further purification. With the aim of forming crosslinked coatings, emulsion copolymerizations of BA/MMA were performed in the presence of various comonomers: 1,3butanediol diacrylate (BuDA), diacetone acrylamide (DAAm), and (2-acetoacetoxy)ethyl methacrylate (AAEM) (Scheme 2). 


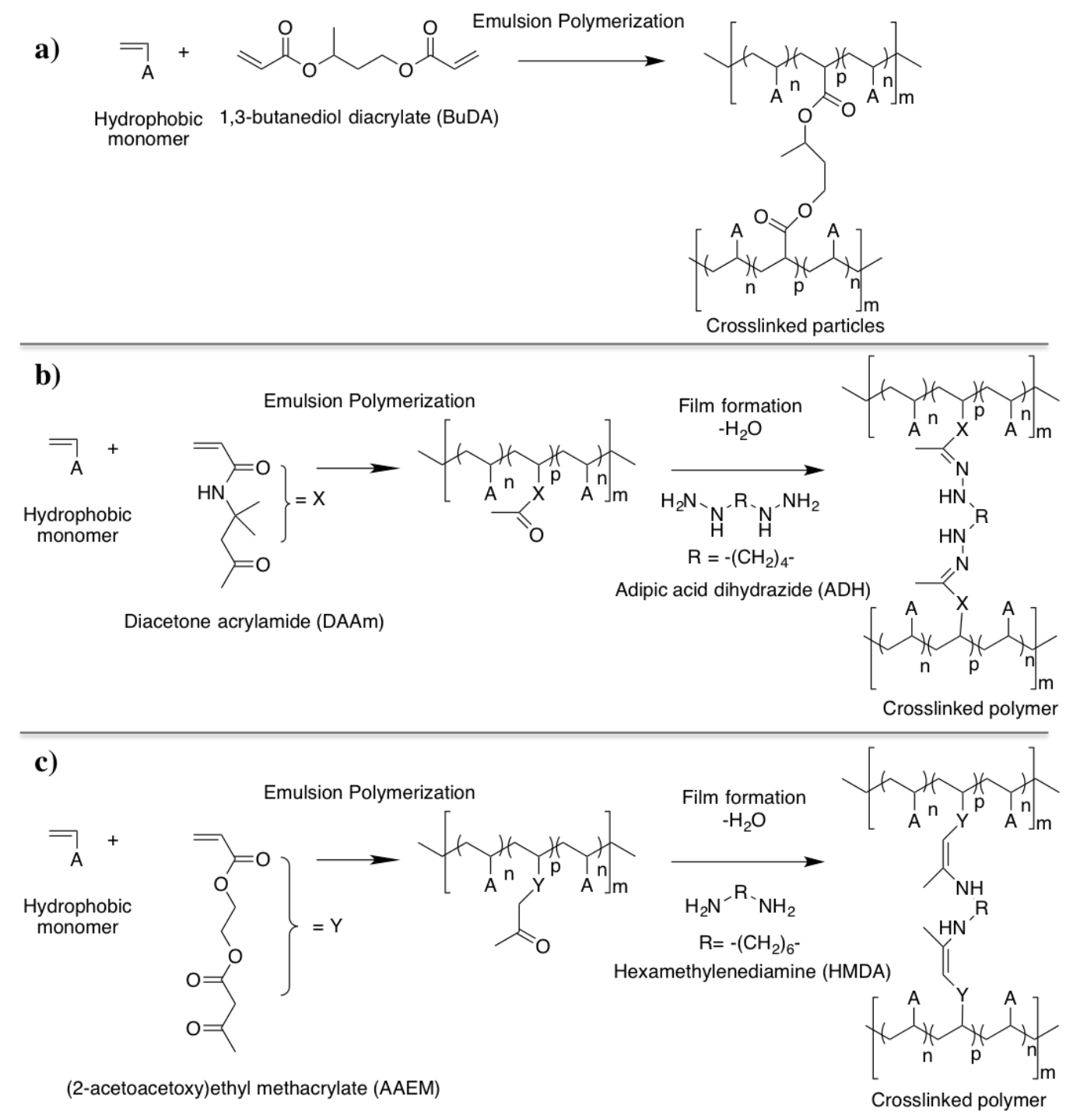

Scheme 2. Chemical structures of 1,3-butanediol diacrylate (BuDA), diacetone acrylamide (DAAm) and (2-acetoacetoxy)ethyl methacrylate (AAEM) co-monomers used in the synthesis of $\mathrm{PMAA}_{2 \mathrm{~K}}$-stabilized latexes to produce crosslinked (BuDA) and crosslinkable (DAAm and AAEM) films. Crosslinking reactions with a) BuDA, b) DAAm and adipic acid dihydrazide (ADH) and c) AAEM and hexamethylenediamine (HMDA).

Again, the experiments were performed at $70{ }^{\circ} \mathrm{C}$ in a $250 \mathrm{~mL}$ double-jacket glass reactor equipped with a condenser. In a typical experiment (Latex 14, DAAm-latex, Table 2), APS (27.1 mg, $7.09 \times 10^{-3} \mathrm{~mol}$ ) was added to a solution of previously synthesized PMAA $2 \mathrm{k}(8.0$ wt.\% aqueous solution, 1.0 wt.\% of PMAA $2 \mathrm{k}$ bom). Water content was adjusted to target a 
final solids content of $40 \mathrm{wt} . \%: \tau=\left(\mathrm{m}_{0-\mathrm{M}}+\mathrm{m}_{0-\mathrm{PMAA} \mathrm{k}}\right) / \mathrm{m}_{0 \text {-total, }}$ with $\mathrm{m}_{0-\mathrm{M}}$ the initial amount of monomers, including BA, MMA and DAAm. The $\mathrm{pH}$ of this solution was adjusted to 7 with a $1 \mathrm{~mol} \mathrm{~L}^{-1} \mathrm{NaOH}$ aqueous solution. BA (23.0 g, $\left.1.79 \times 10^{-1} \mathrm{~mol}, 57.5 \mathrm{wt} . \% \mathrm{bom}\right)$, MMA (15.4 g, $1.54 \times 10^{-1} \mathrm{~mol}, 38.5$ wt.\% bom) and DAAm (1.6 g, 9.45× 10 $0^{-3} \mathrm{~mol}, 4.0 \mathrm{wt} . \%$ bom) were added and the resulting mixture was degassed for 30 min under nitrogen. The polymerization was stopped after $4 \mathrm{~h}$ of stirring at $330 \mathrm{rpm}$. Monomer consumption was measured by gravimetric analysis of samples withdrawn from the polymerization medium at different times. For the other self-crosslinking strategies, DAAm was simply replaced by BuDA or AAEM. The recipes of the different polymerizations performed and the characteristics of the corresponding latexes are given in Table 2.

Table 2. Surfactant-free and (self-)crosslinking latexes stabilized with 1 wt.\% of PMAA $2 \mathrm{k}$ macroRAFT agent

\begin{tabular}{|c|c|c|c|c|c|c|c|c|c|}
\hline Latex & $\begin{array}{l}\text { Functional } \\
\text { comonomer }\end{array}$ & Monomers $^{a}$ & t (h) & $\begin{array}{c}\text { Conv }^{b} \\
(\%)\end{array}$ & $\begin{array}{c}\tau^{c} \\
\text { (wt.\%) }\end{array}$ & $\begin{array}{l}\text { Coag }^{d} \\
\text { (wt.\%) }\end{array}$ & $\begin{array}{c}D_{\mathbf{z}}(\mathbf{n m}) / \\
\text { PDI }^{e}\end{array}$ & $\mathbf{p H}_{\mathbf{f}} f$ & $\begin{array}{l}T_{\mathrm{g}}{ }^{g} \\
\left({ }^{\circ} \mathrm{C}\right)\end{array}$ \\
\hline 13 & BuDA & $\begin{array}{c}\text { BA/MMA/BuDA } \\
(59.0 / 39.3 / 1.7)\end{array}$ & 5.5 & 100 & 40.7 & 0.90 & $\begin{array}{l}198 / \\
0.01\end{array}$ & 7.1 & +0.2 \\
\hline 14 & DAAm & $\begin{array}{c}\text { BA/MMA/DAAm } \\
(57.5 / 38.5 / 4.0)\end{array}$ & 4.0 & 100 & 40.4 & 0.28 & $\begin{array}{l}147 / \\
0.03\end{array}$ & 7.1 & $\begin{array}{l}-18.9 / \\
+21.2\end{array}$ \\
\hline 15 & AAEM & $\begin{array}{c}\text { BA/MMA/AAEM } \\
(57.5 / 38.5 / 4.0)\end{array}$ & 4.0 & 98 & 40.3 & 0.12 & $\begin{array}{l}189 / \\
0.02\end{array}$ & 6.9 & $\begin{array}{c}-16.8 / \\
+7.7\end{array}$ \\
\hline
\end{tabular}

All the experiments were performed at $70{ }^{\circ} \mathrm{C}$, using $2 \mathrm{mmol} \mathrm{L}^{-1}$ of APS and $1 \mathrm{wt} . \%$ of macroRAFT. The pH was initially adjusted to 7 by addition of a $1 \mathrm{M} \mathrm{NaOH}$ solution. ${ }^{a}$ Composition of the initial mixture of hydrophobic monomers. Weight fractions are given in brackets. ${ }^{b}$ Determined by gravimetry. ${ }^{c}$ Solids content $\tau(\%)=\left(\mathrm{m}_{0-\mathrm{M}}+\mathrm{m}_{0 \text {-macroRAFT }}\right) / \mathrm{m}_{0 \text {-total }} .{ }^{d}$ On the basis of the total latex mass. ${ }^{e} D_{\mathrm{z}}$ is the z-average particle diameter and PDI the dispersity factor determined by dynamic light scattering. ${ }^{f}$ Final $\mathrm{pH}$ of the latex. ${ }^{g} T_{\mathrm{g}}$ measured at the midpoint, at $20{ }^{\circ} \mathrm{C} \mathrm{min}^{-1}$.

\section{Analytical Techniques}

(Cryo-)Transmission electron microscopy ((cryo-)TEM). The surfactant-free (selfcrosslinking) latexes were observed in their natural hydrated environment using cryotransmission electron microscopy (cryo-TEM). The diluted samples were dropped onto 300 mesh holey carbon films (Quantifoil R2/1) and immediately quench-frozen in liquid ethane. 
The grid was then mounted on a precooled Gatan 626 specimen holder, and transferred in the Philips CM120 microscope operating at an accelerating voltage of $120 \mathrm{kV}$ (Centre Technologique des Microstructures (CT $\mu$ ), platform of the Université Claude Bernard, Lyon 1, Villeurbanne, France). The number- and mass-average particle diameter $\left(D_{\mathrm{n}}\right.$ and $D_{\mathrm{w}}$, respectively) as well as the particle-diameter dispersity $\left(D_{\mathrm{w}} / D_{\mathrm{n}}\right)$ were determined using ImageJ software counting at least 100 particles. The crosslinked latexes were observed by conventional TEM. The samples were dropped on a carbon-coated copper grid and dried under air. The images were recorded with the same microscope, at an accelerating voltage of $80 \mathrm{kV}$.

Minimum Film Formation Temperature (MFFT). The MFFT was measured according to ASTM D2354 standardized procedure using commercial equipment (MFFT 90, Rhopoint Instruments, St Leonard's-on-Sea, UK). The temperature gradient of the table was adjusted according to the expected MFFT of the latex. The sample was applied as a $75 \mu \mathrm{m}$ wet film thickness on a $50 \mu \mathrm{m}$ PET film in close contact with the MFFT table and allowed to dry (white spirit was used to ensure good contact of the PET film with the table). The latex coating was inspected after 30 min and about 1 h (until total drying time); a minimum of three readings was taken per sample. A latex of known MFFT was used as a control.

Preparation of cross-linked films. One mole of ADH was added for every two moles of DAAm. Specifically, $1 \mathrm{~mL}$ of ADH aqueous solution (7.6 wt.\%) was added while stirring to 9 $\mathrm{mL}$ of Latex 14. (The $\mathrm{pH}$ of the latex was first adjusted to 8.5 to suppress the crosslinking reaction rate. ${ }^{44}$ The dispersion was cast on glass substrates or poly(tetrafluoroethylene), moulds, depending on the technique to be performed (optical transmission or mechanical property analysis, respectively), immediately after adding the crosslinker. Film formation took place under ambient conditions (typically a temperature of $20^{\circ} \mathrm{C}$ and a relative humidity of $40 \%)$. Samples were dried for two days when cast on glass substrates and two weeks when 
cast in poly(tetrafluoroethylene) molds. The same procedure was carried out for Latex 15 using 0.1 wt.\% of hexamethylenediamine (HMDA) as the external cross linker. One mole of HMDA was added for every two moles of AAEM. Specifically, $1 \mathrm{~mL}$ of a 4 wt.\% aqueous solution of HMDA was added to $10 \mathrm{~g}$ of latex (which was first adjusted to a pH of 8.5). Noncrosslinked Latex 2 and Latex 3, as well as internally cross-linked Latex 13 films were also cast for comparison. For some stress/strain analysis experiments, films were formed 21 days after the addition of the crosslinker (ADH or HMDA), rather than film forming immediately.

Determination of the gel fraction. About $5 \mathrm{~g}$ of Latex 13 (Table 2) was cast in a PTFE mould and dried for two weeks. A stochiometric amount of the relevant crosslinker (ADH and HMDA) was added to Latex 14 and Latex 15 (Table 2), respectively, as described in the previous paragraph. Polymer films were obtained by drying $5 \mathrm{~g}$ of latex in PTFE moulds and dried for two weeks at room temperature, and the weight was measured. The gel fraction of the films was obtained after $24 \mathrm{~h}$ of Soxhlet extraction using $250 \mathrm{~mL}$ of THF solvent. The weight of the initial dry film was compared to the weight of the film following the Soxhlet extraction and being dried for three days at room temperature and for $24 \mathrm{~h}$ at $50{ }^{\circ} \mathrm{C}$.

Atomic force microscopy (AFM). Samples were produced by casting on glass substrates $(18 \times$ $18 \mathrm{~mm}^{2}$ ) at room temperature under ambient conditions for two days. Substrates were previously cleaned with acetone and treated inside a UV ozone chamber (Bioforce Nanosciences, model UV.TC.EU.003). The dry film thickness was about $100 \mu \mathrm{m}$. Height images were acquired using an atomic force microscope (Ntegra Prima, NT-MDT, Moscow) with intermittent contact using a silicon cantilever (nominal spring constant of $k=5 \mathrm{~N} \mathrm{~m}^{-1}$ ) near the resonant frequency of $150 \mathrm{~Hz}$. Images were analysed using NOVA software.

UV-Visible Transmission. Measurements were carried out using a double-beam spectrophotometer (UV-2501PC, Shimadzu Europa GmbH, Duisberg, Germany) on $100 \mu \mathrm{m}$ 
films cast on glass substrates after one day of drying and film formation. A bare glass substrate was used in the reference beam. The optical transmission $T$ was determined by the ratio of the intensity of transmitted light $I$ to the intensity of the incident light $I_{0}$ as $T(\%)=$ $\left[I / I_{0}\right] \times 100 \%$

Stress-strain experiments. Latex formulations were cast in poly(tetrafluoroethylene) moulds and allowed to dry for two weeks. Then the films were removed from the moulds and cut into five strips. Prior to the measurement, the dimensions of the strips were measured with digital calipers (typical dimensions of $17 \mathrm{~mm} \times 5 \mathrm{~mm} \times 1 \mathrm{~mm}$ ). Stress-strain measurements were performed on a commercial tensile apparatus (Texture Analyser, MicroSystems, Godalming, UK). The strips were strained at room temperature (ca. $20^{\circ} \mathrm{C}$ ) with a constant crosshead speed of $0.02 \mathrm{~mm} \mathrm{~s}^{-1}$ until they failed. The reported properties are an average of at least five replicate measurements.

Dynamic mechanical analysis (DMA). Latex formulations were cast in poly(tetrafluoroethylene) moulds and allowed to dry for two weeks. The resulting films were cut into strips with typical dimensions of $10 \mathrm{~mm} \times 4 \mathrm{~mm} \times 1 \mathrm{~mm}$. DMA measurements were carried out in air using a Q800 (TA Instruments, New Castle, DE). Experiments were performed under tensile mode at a frequency of $1 \mathrm{~Hz}$ at $0.05 \%$ strain. The temperature was ramped from $-50{ }^{\circ} \mathrm{C}$ to $150{ }^{\circ} \mathrm{C}$ at a rate of $3^{\circ} \mathrm{C} \min ^{-1}$.

Descriptions of additional analytical techniques are provided in the Supporting Information.

\section{Results and discussion}

Synthesis of surfactant-free latexes stabilized with PMAA macroRAFT agents

For the development of surfactant-free latexes suitable for use in coating applications, several 
technical specifications have to be considered. The latexes should contain suitable hydrophilic and hydrophobic monomer combinations (i.e. methacrylic acid (MAA) or acrylic acid (AA) for the hydrophilic monomers and typically n-butyl acrylate (BA), styrene (S) or methyl methacrylate (MMA) for the hydrophobic ones). They should be produced with at least 40 wt.\% solids content and feature particle size typically between 100 and $200 \mathrm{~nm}$. The combination of monomers should be chosen such that the copolymer glass transition temperature is below the ambient temperature during film formation. Thus, particle coalescence will be enabled to yield transparent films. When selecting alternative compounds to low molar mass surfactants, an additional challenge is to reduce the content of hydrophilic species in the formulation to retain hydrophobicity. This restriction is particularly relevant to ensure adequate barrier properties for anticorrosion coatings, which must prevent water sorption and transport. Therefore, a minimum amount of hydrophilic macroRAFT agent was used to ensure the stabilization of film-forming particles produced by a one-pot/two-step emulsion polymerization process.

Based on our works in the field of PISA, ${ }^{42,} 45$ PMAA was selected as the hydrophilic macroRAFT. Two batches were synthesized in water at $80{ }^{\circ} \mathrm{C}, \mathrm{PMAA}_{2 \mathrm{k}}\left(M_{\mathrm{n}}=2140 \mathrm{~g} \mathrm{~mol}^{-1}\right.$, $Ð=1.19)$ and $\mathrm{PMAA}_{4 \mathrm{k}}\left(M_{\mathrm{n}}=3840 \mathrm{~g} \mathrm{~mol}^{-1}, Ð=1.23\right)$. In our previous work, ${ }^{42}$ different compositions of particles (based on PS, PBA or P(M)MA) were successfully obtained via PISA using a PMAA macroRAFT agent (5 to 20 wt.\% with respect to the hydrophobic monomer) at natural $\mathrm{pH}(3)$ at $80^{\circ} \mathrm{C}$.

A set of preliminary experiments was first conducted by simply transposing these conditions to the copolymerization of BA and MMA (55/45 weight ratio, 40 wt.\% solids) employing however a significantly lower amount (0.5 wt.\%) of PMAA macroRAFT (PMAA $4 \mathrm{k}$ ) and APS instead of ACPA as an initiator. An experiment performed at $\mathrm{pH} 2.8$ led to a complete destabilization of the system during the polymerization. As PMAA is not charged at this $\mathrm{pH},{ }^{42}$ 
this PMAA content (0.5 wt.\%) was not enough to ensure an efficient stabilization. The hydrolytic stability of the trithiocarbonate chain end carried by PMAA has been reported to be low at high $\mathrm{pH}$ (after $5 \mathrm{~h}$ at $80{ }^{\circ} \mathrm{C}, \mathrm{pH}=8,86 \%$ of the chains had lost their trithiocarbonate chain ends). ${ }^{42}$ Hence, a high $\mathrm{pH}$ must be avoided since it increases the risk of producing hydrophilic (PMAA) species in the water phase, which could potentially impact the properties of the final films. The $\mathrm{pH}$ was therefore set to 6.1, close to the pKa value of the PMAA macroRAFT. ${ }^{33}$ A stable latex with a $D_{\mathrm{z}}$ of $245 \mathrm{~nm}(\mathrm{PDI}=0.02)$ was obtained with however 5.6 wt. $\%$ of coagulum and a conversion limited to $77 \%$. This preliminary result demonstrated that a very low amount of hydrophilic PMAA macroRAFT may lead to the formation of enough PMAA-b-P(BA-co-MMA) amphiphilic block copolymers capable of stabilizing the formed particles.

Building on this preliminary study, a new set of experiments was performed using a twofold concentration of APS and decreasing the temperature to $70{ }^{\circ} \mathrm{C}$ (Table 1) with the aim of improving both the conversion and the latex stability. In the first experiment (Latex 1), the amount of $\mathrm{PMAA}_{4 \mathrm{k}}$ was raised to 1.5 wt.\%. 96\% conversion was reached in $c a .5 \mathrm{~h}$ and a stable latex with a particle size of $214 \mathrm{~nm}$ (PDI $=0.02$ ) was produced with a negligible amount of coagulum (0.5 wt.\%). The stability of the particles could be further improved by using the same amount of a lower molar mass PMAA macroRAFT (PMAA $2 \mathrm{k}$ in Latex 2, Table 1). Smaller particles were obtained $\left(D_{z}=149 \mathrm{~nm}\right.$, PDI $\left.=0.02\right)$ although the monomer composition was slightly modified (BA/MMA, weight ratio of 60/40). Quantitative conversion was obtained in $4 \mathrm{~h}$ with again almost no coagulum (0.1 wt.\%). In an attempt to decrease the hydrophilic species amount further, another experiment (Latex 3) was conducted with 1 wt.\% of PMAA 2 . Again, a stable latex was formed and quantitative conversion was observed. As could be expected, larger particles $(196 \mathrm{~nm})$ compared to the use of $1.5 \mathrm{wt} . \%$ of PMAA $_{2 \mathrm{k}}$, were obtained (Latex 2, $149 \mathrm{~nm}$ ) due to the formation of less stabilizer. Statistical 
analyses of cryo-TEM images of these latexes (Figure 1) indicate that particle sizes were typically ca. $20 \mathrm{~nm}$ smaller than the hydrodynamic sizes measured by dynamic light scattering. The observed discrepancy between the particle sizes determined by the two techniques may be the result of the contribution of the PMAA corona to the measured size. The minimum film formation temperature (MFFT) of Latex 2 and Latex 3 were below room temperature $\left(5{ }^{\circ} \mathrm{C}\right.$ and $2{ }^{\circ} \mathrm{C}$, respectively, Table 1$)$. Both latexes produced transparent and colorless films as shown in Figure 2.
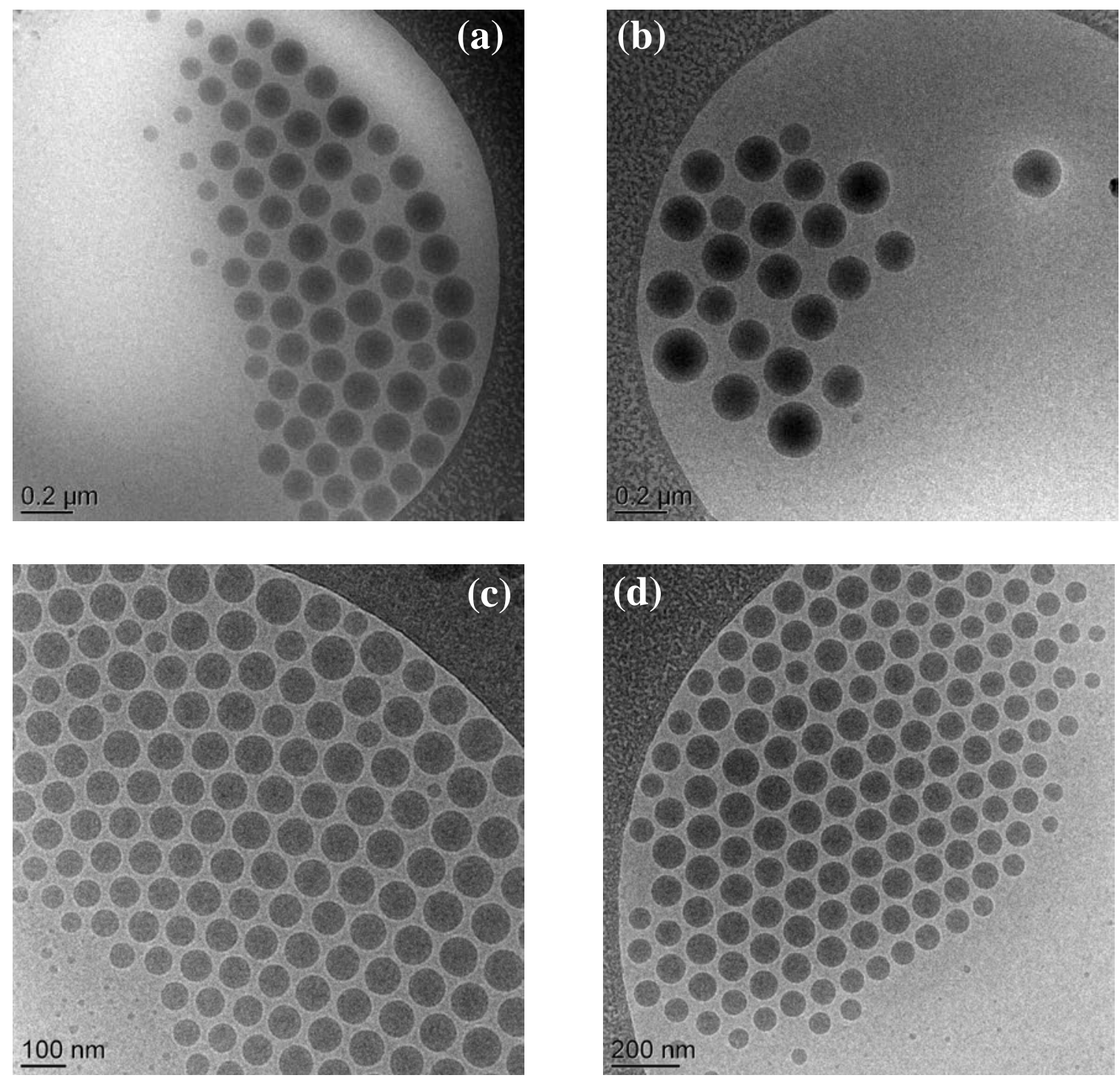

Figure 1. Cryo-TEM micrographs of (a) Latex $2\left(D_{\mathrm{n}}=124 \mathrm{~nm} ; D_{\mathrm{w}} / D_{\mathrm{n}}=1.07\right)$, (b) Latex 3 $\left(D_{\mathrm{n}}=176 \mathrm{~nm} ; D_{\mathrm{w}} / D_{\mathrm{n}}=1.03\right)$, (c) Latex $10\left(D_{\mathrm{n}}=69 \mathrm{~nm} ; D_{\mathrm{w}} / D_{\mathrm{n}}=1.12\right)$ and (d) Latex $12\left(D_{\mathrm{n}}\right.$ $=70 \mathrm{~nm} ; D_{\mathrm{w}} / D_{\mathrm{n}}=1.18$ ) (See Table 1 for more information on these samples). $D_{\mathrm{n}}$ and $D_{\mathrm{w}} / D_{\mathrm{n}}$ 
were determined by counting at least 100 particles for each sample.

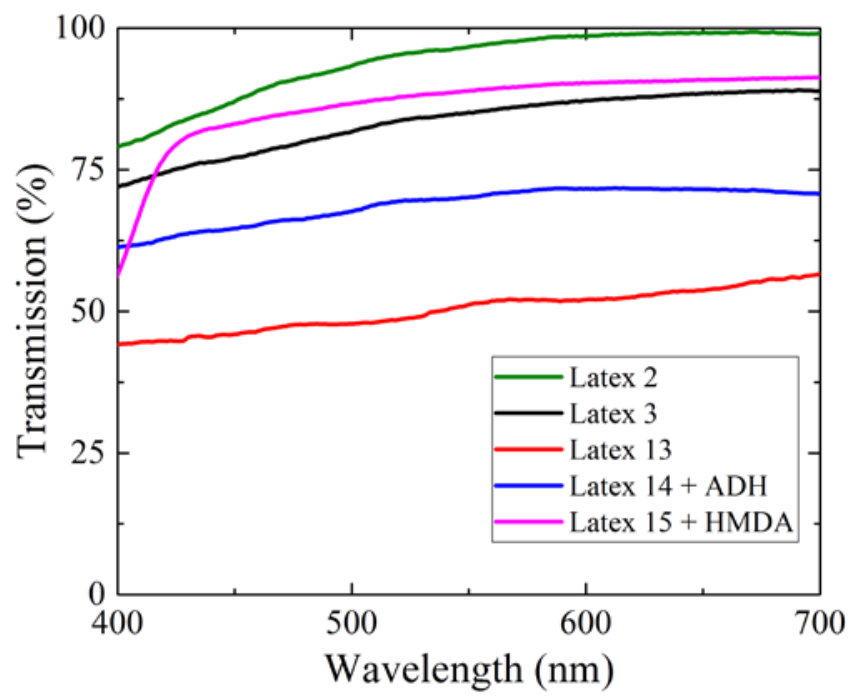

Figure 2. Optical transmission spectra of various films in the visible range (400 - $700 \mathrm{~nm})$. The relatively flat spectra indicate that the films are colorless. (See Tables 1 and 2 for more information on these samples.)

The glass transition temperatures $\left(T_{\mathrm{g}}\right)$ of Latex 2 and Latex 3 spanned a broad range of temperatures (between -40 and $+40{ }^{\circ} \mathrm{C}$, see Table S1 and Figure S1 in Supporting Information). This result was ascribed to a probable compositional drift (not characterized here) occurring during the copolymerization of MMA and BA. Indeed, the reactivity ratios (in bulk: $r_{\mathrm{BA}}=0.36$ and $r_{\mathrm{MMA}}=2.55^{46}$ ) combined with the higher solubility in water of MMA (1.5 $10^{-1} \mathrm{~mol} \mathrm{~L}^{-1}{ }^{47}$ vs $6.410^{-3} \mathrm{~mol} \mathrm{~L}^{-1}{ }^{48}$ ) will likely lead to the formation of copolymers initially enriched in MMA. In order to counterbalance the effect of this compositional drift on Tg, an experiment similar to Latex 3 under semi-batch conditions was carried out (Latex 4, Table 1). $97 \%$ conversion was reached. As expected, one well-defined $T_{\mathrm{g}}$ of $1.1{ }^{\circ} \mathrm{C}$ was measured, thus confirming the effect of composition drift on $T_{g}$ (Figure S1 in Supporting Information). The switch from batch to semi-batch methods caused the particle sizes to decrease from $196 \mathrm{~nm}$ (Latex 3) to $126 \mathrm{~nm}$ (Latex 4). 
While keeping batch emulsion polymerization conditions, another way to minimize the effect of the composition drift on the final $T_{g}$ is to use styrene (S) instead of MMA (in emulsion: $r_{\mathrm{BA}}=0.689 / r_{\mathrm{S}}=0.164^{49}$ or $\left.r_{\mathrm{BA}}=0.75 / r_{\mathrm{S}}=0.2^{50}\right)$. Latex 5 was therefore synthesized using the same conditions as Latex 3 (stabilized with 1.0 wt.\% of PMAA $2 \mathrm{k}$ macroRAFT, Table 1), by copolymerizing a monomer mixture of BA/S (55/45 weight ratio). The resulting particles were noticeably smaller $\left(D_{\mathrm{z}}=89 \mathrm{~nm}\right)$, and their size distribution remained narrow $(\mathrm{PDI}=$ 0.04). The conversion was quantitative, and the amount of coagulum was very low (0.01 wt.\%). Decreasing further the amount of PMAA $2 \mathrm{k}$ to 0.75 wt.\% (Latex 6) also produced a stable latex. The reason for obtaining much smaller particles in the case of BA/S mixture compared to BA/MMA mixture is probably a result of different nucleation efficiencies between the two systems. ${ }^{22}$ As shown by the kinetics (Figure S2 in Supporting Information), a longer nucleation period is observed when styrene is employed. A comparable behavior was observed several times in the literature, particularly in PISA systems. ${ }^{22,42,51-52}$ According to the block copolymer formation assumed in the present systems, this difference in nucleation time may be explained by the chain growth step taking place in the aqueous phase, before the in situ formed amphiphilic block copolymers reach the appropriate hydrophilic/hydrophobic molar mass balance to be surface active. Indeed, the time needed for the $\mathrm{P}(\mathrm{S}-\mathrm{co}-\mathrm{BA})$ hydrophobic block to reach this critical molar mass depends on the respective solubility of both monomers in water, the average rate constant of propagation of the comonomer mixture (related to the reactivity ratios), and finally the apparent chain transfer constant to the PMAA macroRAFT agent. Considering the reactivity ratios of BA/S and BA/MMA comonomers systems (see above), the very first chains formed will be richer in S and MMA, respectively. Besides, the chain transfer constant of a polymethacrylyl macroradical to a trithiocarbonateended polymethacrylate is significantly lower than that of a polystyryl macroradical. ${ }^{53}$ Even though the concentration of styrene in water is much lower than that of MMA (solubility in 
water of S and MMA of $4.310^{-3} \mathrm{~mol} \mathrm{~L}^{-1} 54$ and $1.510^{-1} \mathrm{~mol} \mathrm{~L}^{-155}$, respectively), the presence of styrene favors the release of (and reinitiation by) the polymethacrylyl leaving group of the PMAA macroRAFT agent. ${ }^{56}$ The situation is different in the case of the BA/MMA mixture for which a single transfer is enough to create a hydrophobic block long enough to be surface active, which also favors homogeneous nucleation. In contrast, for the case of BA/S, the formation of numerous nuclei is consistent with the formation of much smaller particles.

As expected, the use of styrene instead of MMA led to polymer chains with a well-defined $T_{\mathrm{g}}$ (16.8 ${ }^{\circ} \mathrm{C}$ for Latex 6, Table S1), confirming the absence of composition drift. Films could be formed from both Latex 5 and Latex 6, however, the films were not fully transparent, because of light scattering attributed to structural heterogeneity (e.g. surface roughness and nanovoids).

In order to control the compositional drift and to avoid the film opacity, a monomer mixture based on BA, S and MMA (BA/S/MMA 60/25/15 weight ratio) was further employed (Latex 7, Table 1) while keeping the conditions identical to those used for Latex 6. A stable latex was formed and the film gained in transparency. However, the borders remained opaque. The MMA content was further increased to 25 wt.\% (Latex 8, BA/S/MMA 60/15/25 weight ratio), giving a totally transparent film. Although already quite low (0.47 wt.\%), the amount of coagulum was decreased to 0.37 wt. $\%$ and 0.08 wt.\% by increasing the content of PMAA macroRAFT to 1 wt.\% in Latex 9 and 1.5 wt.\% in Latex 10, respectively (Table 1). This led to improved stability of the final latexes that feature isometric particles with final particle sizes decreasing with the amount of PMAA macroRAFT employed (152 nm, $128 \mathrm{~nm}$, and 96 $\mathrm{nm}$ when going from Latex 8 to Latex 10). Working with higher concentration of styrene (30 wt.\%) using either 1.0 or 1.5 wt.\% of macroRAFT agent (Latex 11 and Latex 12, respectively) did not bring additional benefit in terms of particle size and stability (Table 1 and Table S1). Moreover, cryo-TEM images of Latex 10 and 12 (both prepared with 1.5 wt.\% 
of $\mathrm{PMAA}_{2 \mathrm{k}}$ ) shows quite broad particle size distribution (Figure 1). Both latexes have a MFFT of $2{ }^{\circ} \mathrm{C}$ (Table S1) and led to the formation of transparent films.

To validate the quantitative consumption of the PMAA macroRAFT and its full involvement in the formation of block copolymer stabilizer, SEC analyses were performed on the final latexes (Latexes 2, 3, 10 and 12 in Table 1) in order to detect potential traces of remaining PMAA macroRAFT. The overlay of the SEC traces of the starting PMAA $2 \mathrm{k}$ and the polymers formed in the different latexes (Figure S3 in Supporting Information) showed the presence of only traces of residual macroRAFT. The consumption of the PMAA macroRAFT during the formation of the particles was further confirmed by surface tension measurements performed on the Latex 3. A calibration curve was constructed by measuring the surface tensions of pure water and of solutions of PMAA with increasing concentrations (Figure S4 in Supporting Information). Comparing the measurement of Latex 3, it was concluded that only a trace amount (0.8 mol.\%) of residual PMAA macroRAFT agents was present in the aqueous phase.

It is worth noting that the viscosity of the various synthesized latexes remains low, in the range of industrial requirements (<90 cP, Table S1 in Supporting Information), whatever the composition of the particles or the macroRAFT used to ensure their stabilization.

To gain further insight into these latexes and to evaluate their suitability for applications, a stability test was undertaken on Latex 3, which may be the best candidate for a barrier coating because it has the lowest amount of hydrophilic compound used for its synthesis (1.0 wt.\% of macroRAFT agent). In order to simulate the aging of Latex 3 at room temperature over a long period of time, a stability test at $50{ }^{\circ} \mathrm{C}$ was carried out for one month (Table S2 in Supporting Information). The initial sample was white and stable. After one day of heating at $50{ }^{\circ} \mathrm{C}$, neither sedimentation, nor separation into layers was observed. However, a skin appeared at the interface between the latex and air. During the one-month study, this skin remained 
unchanged. The $\mathrm{pH}$ and the viscosity did not change from the initial values (Table S2). The size of the particles only slightly decreased from $204 \mathrm{~nm}$ to $197 \mathrm{~nm}$ showing that this latex should be stable at room temperature over a long period of time.

Synthesis of surfactant-free and (self-)crosslinking latexes stabilized with $P M A A_{2 k}$ macroRAFT agent

To improve the film properties, such as the mechanical stiffness, the chemical stability and the solvent resistance, different crosslinking strategies were implemented (Scheme 2). We found that our synthetic strategy based on the use of hydrophilic macroRAFT is compatible with the well-established film crosslinking strategies for surfactant-based film-forming latexes. ${ }^{37}$ In all cases, the modified recipes were based on that of Latex 3, using 1 wt.\% of PMAA $_{2 \mathrm{k}}$ macroRAFT for a BA/MMA monomer mixture (60/40 weight fraction, 40 wt.\% solids content). A latex with crosslinked particles (Latex 13) was synthesized along with two cross-linkable latexes (Latex 14 and Latex 15) that were able to undergo crosslinking during film formation.

In the first case, a di-acrylate, BuDA (1.7 wt.\%), was used as a crosslinker during the polymerization (Latex 13, Table 2) to yield crosslinked particles (Scheme 2a). A latex similar in size to Latex 3 ( $D_{z}=198 \mathrm{~nm}$ and $196 \mathrm{~nm}$, respectively) was obtained. Differential scanning calorimetry (DSC) analysis of the resulting latex showed only one $T_{\mathrm{g}}\left(+0.2^{\circ} \mathrm{C}\right)$ in this case (Table 2). The gel fraction of the latex was 96.9 wt.\% (Table S3), showing the efficiency of the crosslinking. Despite their low $T_{\mathrm{g}}$, the crosslinked particles could be observed by conventional TEM (Figure 3a). The final particles were film forming, but the transparency was reduced with respect to Latex 3 (Figure 2), probably because of reduced coalescence arising from chains being restricted by crosslinks, as will be discussed later. 
The second strategy relied on the use of a ketone-functional monomer allowing a crosslinking reaction to occur during film-formation by the addition of a specific reagent. Either DAAm (4 wt.\%, Latex 14 in Table 2) or AAEM (4 wt.\%, Latex 15) were used in the synthesis. Both experiments reached high conversion (100\% and 98\%, respectively). NMR studies indicated that DAAM and AAEM were efficiently incorporated since only traces of DAAm could be detected while AAEM was quantitatively consumed. These two latexes were both stable, with a low amount of coagulum ( $<0.3$ wt.\%). Compared to their non-functional homologues (Latex 3, $D_{z}=196 \mathrm{~nm}$ ), the particles were smaller when DAAm was used (Latex 14, $D_{\mathrm{z}}=147$ $\mathrm{nm}$ ) and similar in size with AAEM (Latex 15, $D_{\mathrm{z}}=189 \mathrm{~nm}$ ) (see also the cryo-TEM images in Figures 3b and 3c). Like Latex 3, two broad glass transitions were observed (Table 2). An aqueous solution of adipic acid dihydrazide (ADH) or hexamethylenediamine (HMDA) was added to Latex 14 and Latex 15, respectively, to induce crosslinking during film formation (Schemes 2b and 2c, respectively). Transparent films exhibiting gel fractions of 100 wt.\% (Table S3 in Supporting Information and Figure 2) were obtained in both cases showing the efficiency of the crosslinking strategies. Both types of films retained cohesion and integrity when swollen in the THF. In comparison, the internally crosslinked particles, synthesized using $\mathrm{BuDa}$ (Latex 13), had a slightly lower gel fraction of 96.9 wt.\%. These films disintegrated in THF, but the particles did not dissolve. 

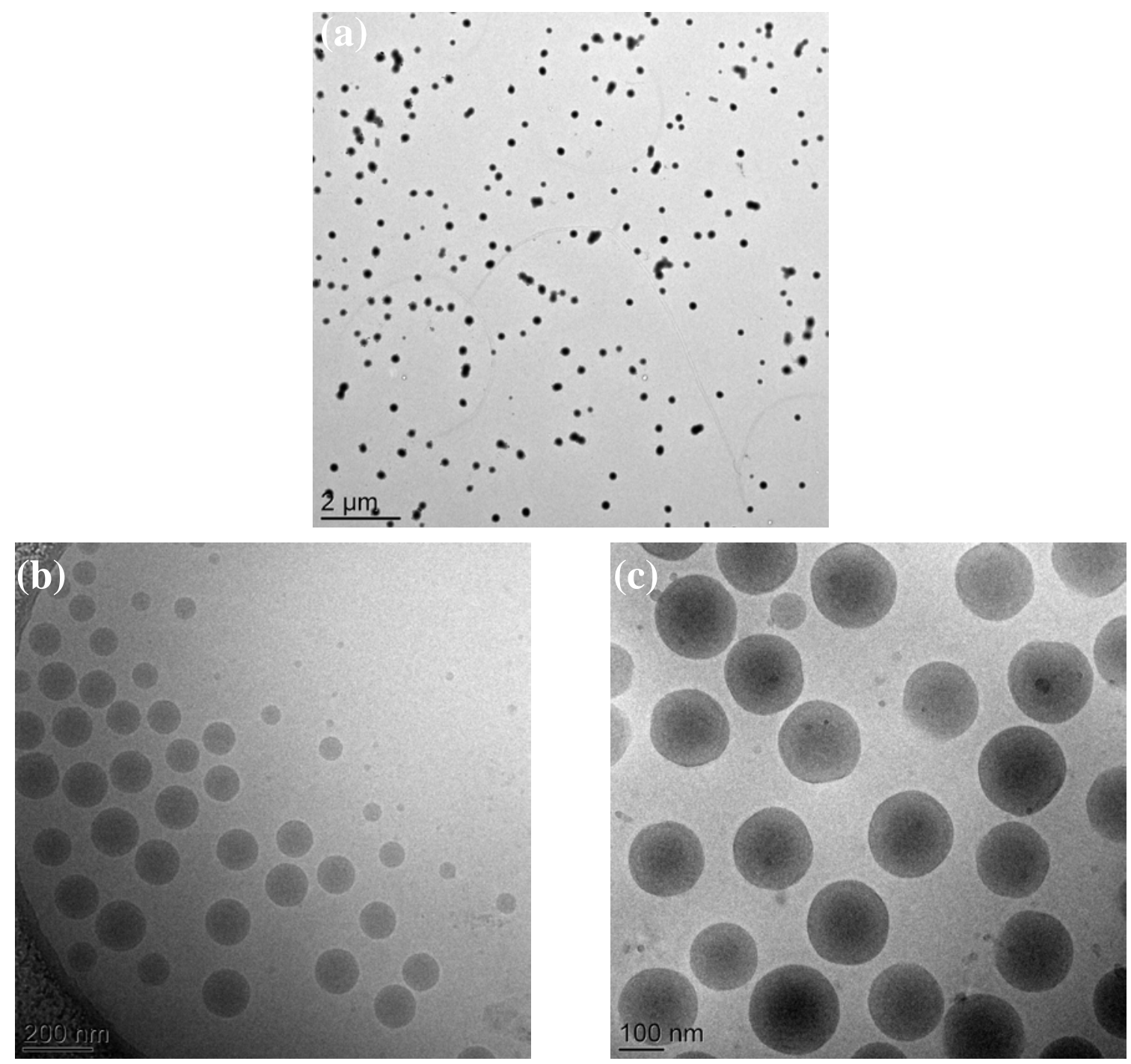

Figure 3. (a) TEM image of the final crosslinked Latex 13 (BuDA-crosslinked counterpart of Latex 3). Cryo-TEM images of the final self-crosslinkable (b) Latex 14 (DAAmfunctionalized counterpart of Latex 3) and (c) Latex 15 (AAEM-functionalized counterpart of Latex 3).

\section{Film Micro- and Nanostructures}

In order to study the influence of the different cross-linking strategies on the film formation process and the final mechanical properties, a set of formulations was selected. A reference latex was chosen (Latex 3) and compared with its cross-linked version using BuDA (Latex 13), and its crosslinkable versions using AAEM (Latex 15) and DAAm (Latex 14) 
functionality. As seen in the AFM images in Figure 4, all four formulations form films, but particles are apparent in the first three formulations; particle identity is less clear in Latex 14. Latex 3 and Latex 15 (Figures 4a and 4c) show similar structures (densely-packed particles with regions of hexagonal ordering and clear particle boundaries), which is an indication that the AAEM functionalization does not have a strong influence on the film formation process. The remnants of individual particles at the film surface are apparent in the topographic line scans presented in Figure 4e. The particle height is on the order of $10-20 \mathrm{~nm}$ (much less than the particle diameters), which indicates particle flattening during film formation. The amount of particle flattening at a particular time is inversely related to the polymer viscosity. ${ }^{57}$ In contrast, the particles in the Latex 13 film (Figure 4b) retain their spherical shape after film formation, which is apparent in the topography (Figure 4e). Nanovoids and several microcracks between particles are apparent on the surface, which reveals that particles have not coalesced, despite a $T_{\mathrm{g}}$ value below the ambient temperature (Table 2). This restricted film formation explains the loss of film transparency presented previously in Figure 2. Voids and cracks scatter light and reduce the fraction that is transmitted. Latex 14 presents the opposite nanostructure: a complete loss of particle identity with coalescence leading to greater homogeneity (Figure 4d), with a reduced surface roughness (Figure 4e). 


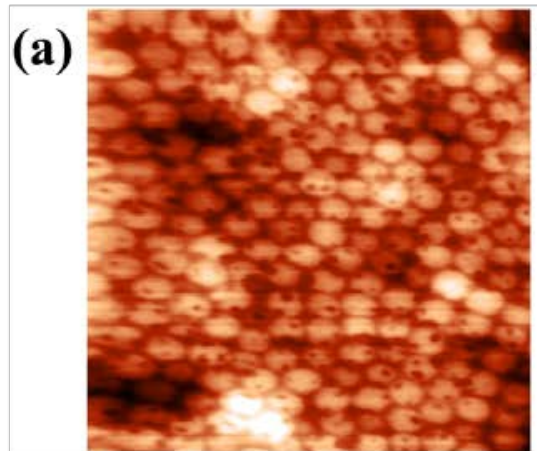

(b)
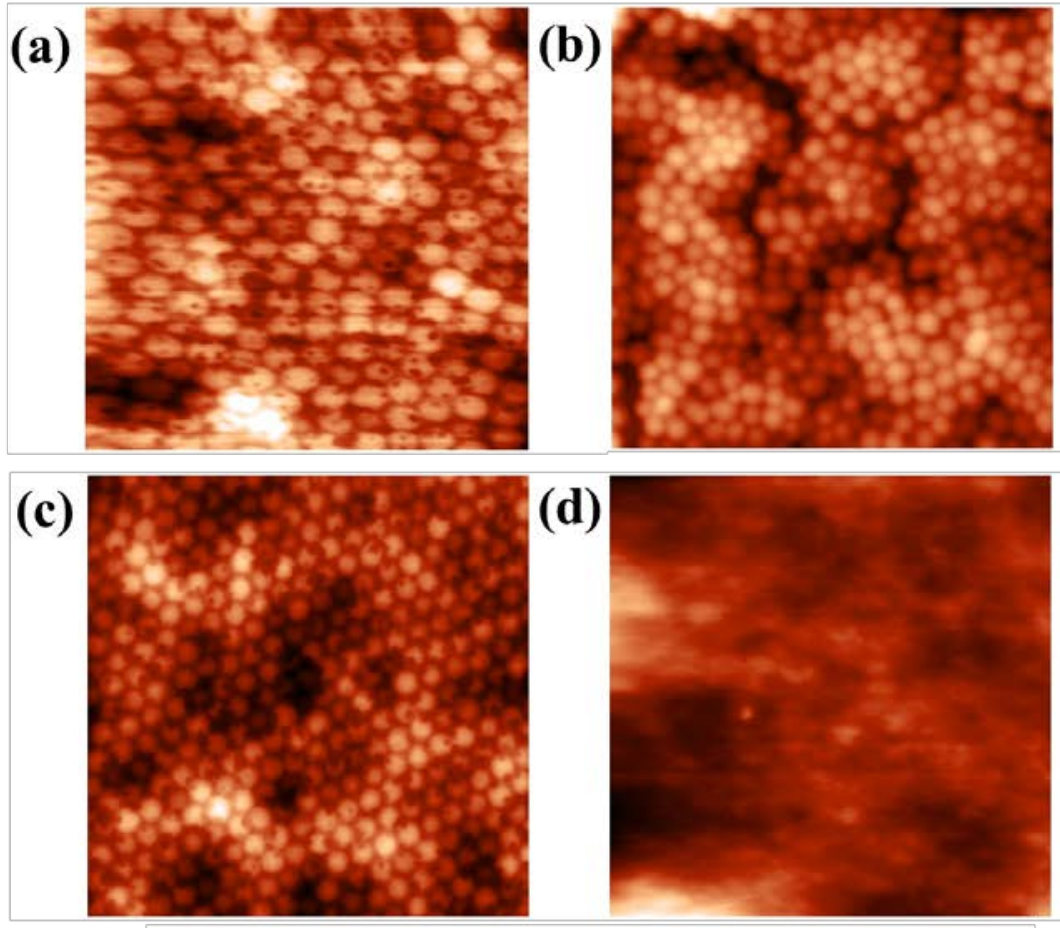

(e)

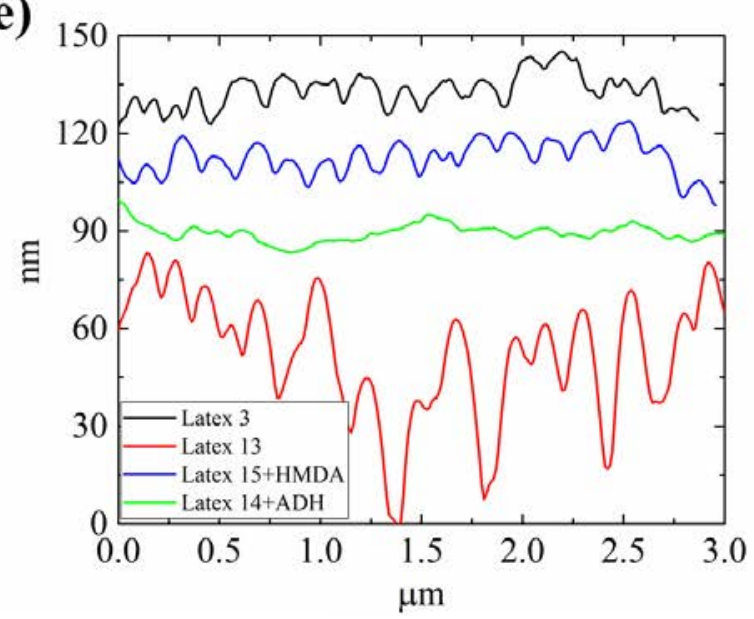

Figure 4. Atomic force microscopy height images $\left(3 \times 3 \mu^{2}\right)$ of the surface of films of (a) Latex 3, (b) Latex 13 (containing BuDA), (c) Latex 15 (crosslinked with HMDA) and (d) Latex 14 (crosslinked with ADH). (e) Topographic cross-sectional scans travelling $3 \mu \mathrm{m}$ across the surface of the four latex films, as indicated in the legend. (The vertical position of each scan in relation to the others is arbitrary.) 
These various film structures reveal the effects of the three types of crosslinking. Particles are internally crosslinked with BuDA (Latex 13), and hence their deformation is restricted and chain interdiffusion is prevented (Scheme 3a). The structure of the film functionalized with DAAm (Latex 14) indicates that particle deformation preceded any significant crosslinking, and interdiffusion was not inhibited (Scheme 3b).

(a)

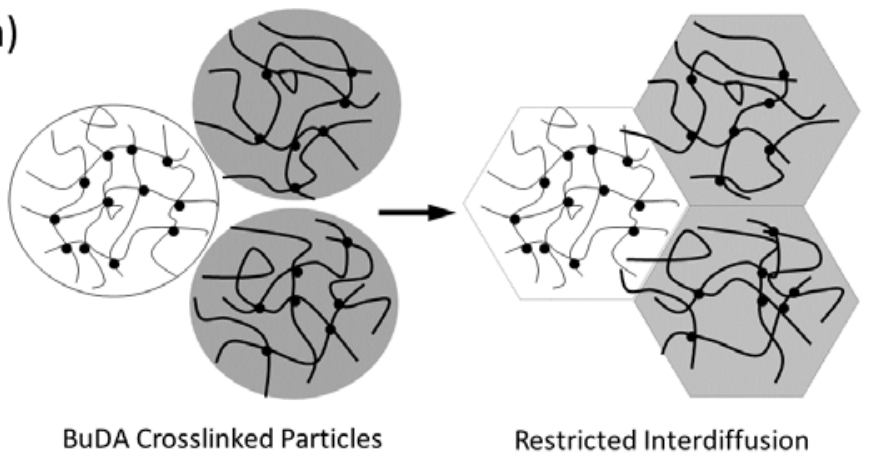

(b)

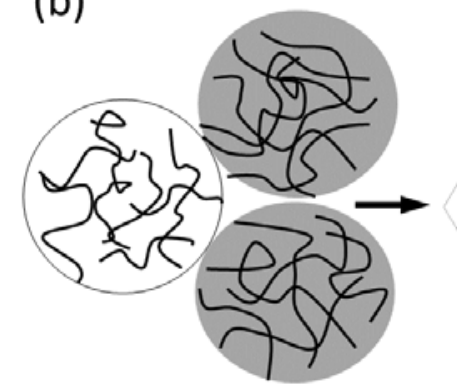

Non-crosslinked particles

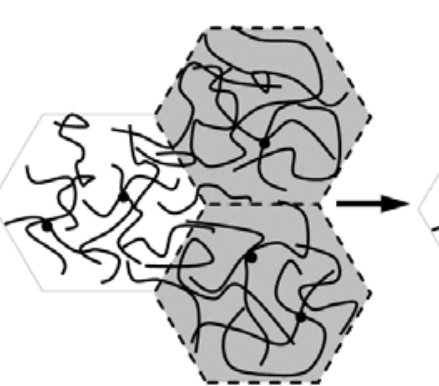

Interdiffused with Limited Crosslinking

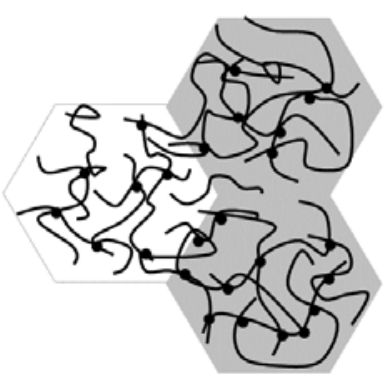

Fully Crosslinked

Scheme 3. Polymer chain (inter)diffusion in the films formed from (a) BuDA-crosslinked particles (Latex 13) and (b) AAEM (Latex 15) and DAAm-functionalized (Latex 14) particles, after addition of HMDA (Latex 15) and ADH (Latex 14).

\section{Large-Strain Properties of (Self-)Crosslinked Films}

According to the very high gel fraction values, the different crosslinking strategies were effective in Latex 13 (internally crosslinked) and in Latexes 14 and 15 (crosslinking during film formation). The influence of the crosslinking on Latex 14 is clearly evident on the 
mechanical properties shown in Figure 5a. After crosslinking, the material fails at a significantly higher stress, and the Young's modulus (determined from the slope in the low strain regime) increases from $10 \mathrm{MPa}$ to $34 \mathrm{MPa}$. At the same time, there is some loss of extensibility with the strain at failure reducing to about $200 \%$, as is expected for a more rigid material.

The differences in the nanostructure shown in Figure 4 correlate with clear differences in the mechanical properties for the four materials, as is shown in Figure 5b. Care must be taken when comparing the four polymers, because there are differences in both their composition and their $T_{\mathrm{g}}$, in addition to differences in the crosslinking densities. In comparison to the noncrosslinked latex (Latex 3), the latex internally crosslinked with BuDA (Latex 13) shows enbrittlement, with a significantly lower tensile strength and strain at failure. The latter is reduced to $24 \%$, compared to $572 \%$ for Latex 3 . The Latex 13 sample fails at a very low strain, before reaching a yield point. This embrittlement and loss of cohesion in the Latex 13 film is consistent with the inhibited particle coalescence and nanocracks found in AFM analysis. Values of the measured mechanical properties are listed in Table 3.

Crosslinking through functionalization with AAEM (Latex 15) results in films with a high strain at failure, which can be explained by greater cohesion resulting from interfacial crosslinking between particles. Although some particle boundaries were seen in the AFM images for Latex 15, the mechanical properties reveal that there is sufficient interdiffusion to provide cohesion, and crosslinking to raise the elastic modulus. The films formed from Latex 14 (functionalized with DAAm) show the highest Young's modulus, tensile strength and yield point out of the four materials. This film had the most homogeneous structure and full coalescence between particles. The high modulus indicates that it achieved the highest crosslinking density compared to the two other crosslinked systems. 
The elastic modulus of a crosslinked rubbery polymer is expected from standard theory ${ }^{34}$ to increase in proportion to the crosslink density. If the crosslinking reactions are complete, then the crosslink density will be proportional to the number of functional groups in the composition. Per every 100 g of Latex 14 and Latex 15, 4 wt.\% (bom) of the functional monomer was used. Each monomer will contribute to one-half of a crosslink formed by the external crosslinker. Thus, the DAAm in Latex 14 will contribute 0.0047 mol of crosslinks per 100 g polymer, whereas the AAEM in Latex 15 will contribute 0.0036 mol of crosslinks per $100 \mathrm{~g}$, if crosslinking is complete. In comparison, $100 \mathrm{~g}$ of Latex 13 contains $1.7 \mathrm{wt} \%$ (bom) of BuDA, and each BuDA monomer can form a single crosslink. Thus, the BuDA in Latex 13 will contribute 0.0035 mol of crosslinks per 100 g. The compositions of the three latexes suggest that Latex 14 will have the highest crosslink density and resulting highest Young's modulus. This is what is found in the experiment. The compositions of Latex 13 and 15 predict that they should have similar crosslink densities. The higher modulus value obtained for Latex 15 suggests that its crosslinking reaction was more efficient. 
(a)

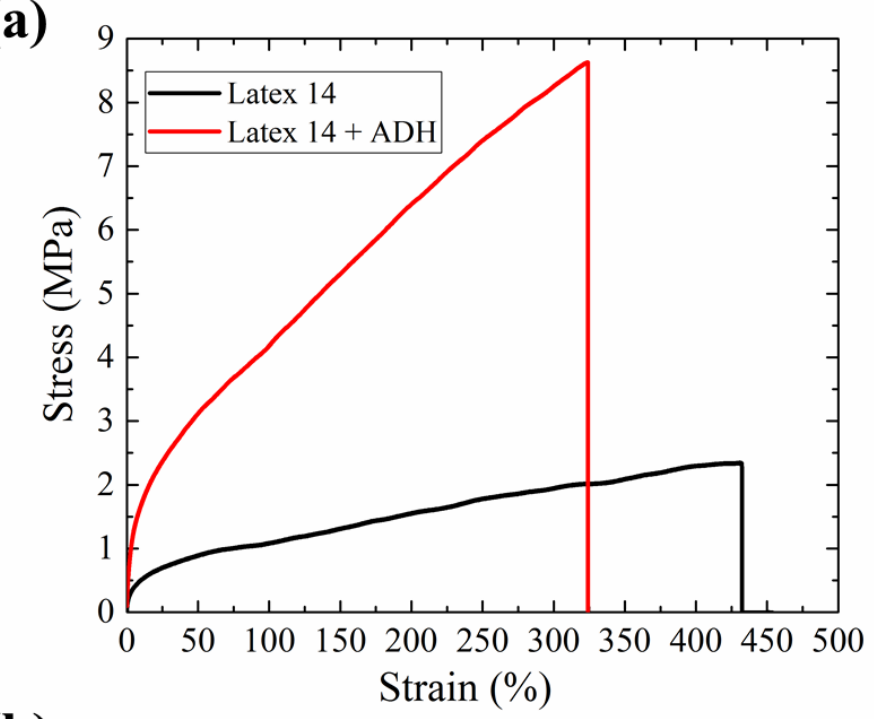

(b)

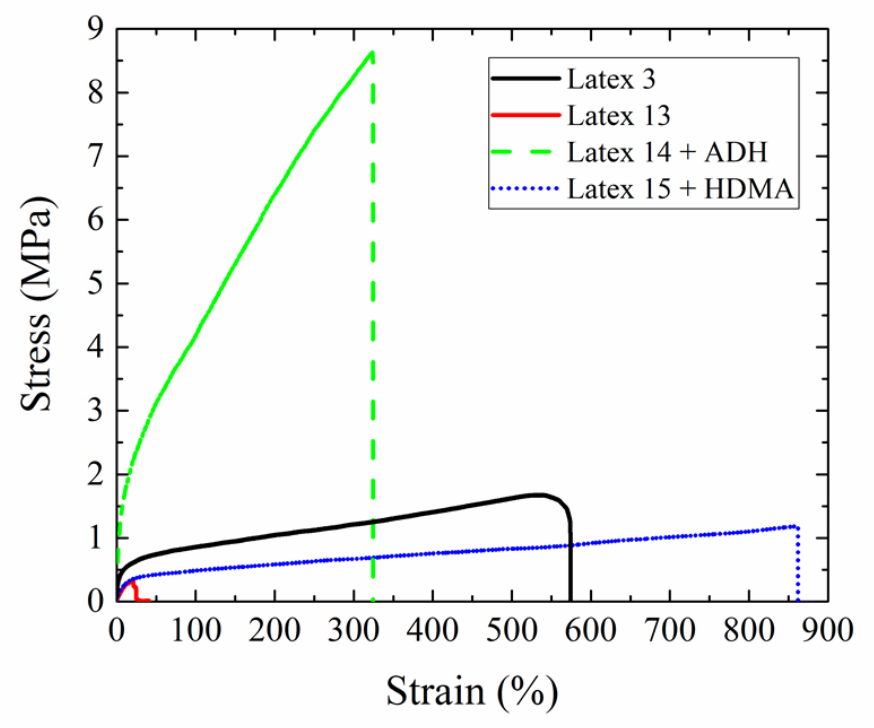

Figure 5. Representative large-strain deformation data from latex films with different crosslinking functionalities. (a) Comparison of Latex 15 with and without the addition of ADH crosslinker. (Black line $=$ original; Red line $=$ with $\mathrm{ADH}$ ) (b) Comparison of the nonfunctionalized polymer (Latex 3) and crosslinked polymers (Latex 13, 14 and 15), as is indicated in the legend. 
Table 3. Mechanical properties (large-strain and linear viscoelastic) of latex films with different cross-linking functionalities

\begin{tabular}{|c|c|c|c|c|c|c|c|c|}
\hline Latex & $\begin{array}{c}\text { Young's } \\
\text { modulus } \\
\text { (+/-error) } \\
\text { (MPa) }\end{array}$ & $\begin{array}{c}\text { Tensile } \\
\text { strength } \\
\text { (+/-error) } \\
\text { (MPa) }\end{array}$ & $\begin{array}{c}\begin{array}{c}\text { Strain at } \\
\text { failure }\end{array} \\
\text { (+/-error) } \\
\text { (\%) }\end{array}$ & $\begin{array}{c}\text { Yield point } \\
\text { (+/-error) } \\
\text { (MPa) }\end{array}$ & $\begin{array}{c}E^{\prime} \text { at } 2{ }^{\circ} \mathrm{C} \\
\text { (MPa) }\end{array}$ & $\begin{array}{c}E^{\prime} \\
\text { at } 80^{\circ} \mathrm{C} \\
(\mathrm{MPa})\end{array}$ & $\begin{array}{c}\text { E’'at } 20 \\
{ }^{\circ} \mathrm{C} \\
\text { (MPa) }\end{array}$ & $\begin{array}{l}T_{g} \text { from } \\
\text { E’' }^{\prime}\left({ }^{\circ} \mathrm{C}\right)\end{array}$ \\
\hline 3 & $\begin{array}{l}10 \\
(1)\end{array}$ & $\begin{array}{c}1.56 \\
(0.29)\end{array}$ & $\begin{array}{c}572 \\
(224)\end{array}$ & $\begin{array}{c}0.47 \\
(0.02)\end{array}$ & 146 & 0.6 & 68 & $\begin{array}{l}-25.2 \\
-0.5\end{array}$ \\
\hline 13 & $\begin{array}{c}3 \\
(1)\end{array}$ & $\begin{array}{c}0.34 \\
(0.22)\end{array}$ & $\begin{array}{c}24 \\
(11)\end{array}$ & - & 46 & 2.0 & 50 & $\begin{array}{c}-18.3 \\
3.5\end{array}$ \\
\hline $\begin{array}{l}14+ \\
\mathrm{ADH}\end{array}$ & $\begin{array}{l}34 \\
(5)\end{array}$ & $\begin{array}{c}7.08 \\
(1.60)\end{array}$ & $\begin{array}{l}260 \\
(70)\end{array}$ & $\begin{array}{c}1.12 \\
(0.16)\end{array}$ & 174 & 2.2 & 64 & $\begin{array}{c}-22.5 \\
5.7\end{array}$ \\
\hline $\begin{array}{c}15+ \\
\text { HMDA }\end{array}$ & $\begin{array}{c}5 \\
(2)\end{array}$ & $\begin{array}{c}1.15 \\
(0.17)\end{array}$ & $\begin{array}{c}877 \\
(227)\end{array}$ & $\begin{array}{c}0.30 \\
(0.07)\end{array}$ & 270 & 1.4 & 78 & $\begin{array}{c}-24.7 \\
14.7\end{array}$ \\
\hline
\end{tabular}

Additional experiments investigated the extent to which crosslinking occurs in the wet latex at a pH of 8 during storage. Latex 14 and 15 were aged at room temperature for 21 days before the film formation of samples for mechanical analysis. For each crosslinking chemistry, the Young's modulus of the films is significantly higher when the formulation was aged for 21 days. This result provides evidence for crosslinking reactions in the wet latex prior to film formation (See data in Figure S5 and Table S4). The strain at failure and the toughness of Latex 14 (with the DAAm + ADH reaction) both build after 21 days, which indicates that the intra-particle crosslinking in the wet latex did not suppress the film coalescence appreciably. In Latex 15 (with the AAEM + HMDA reaction), the yield point rises sharply as a result of the crosslinking but the failure stress is relatively low and there is a large drop in the strain at failure. This loss of extensibility is indicative of a weakening of the particle/particle boundaries, which can be attributed to the intra-particle crosslinking restricting the particle coalescence. These results demonstrate that the age of the formulation can be used as a parameter to adjust the mechanical properties of the films. In contrast, there is minimal change in Latex 13 (internally crosslinked with BuDA) because the intra-particle crosslinking is complete in both cases prior to film formation. 


\section{Linear Viscoelasticity of (Self-)Crosslinked Films}

To explore the low-strain deformation, DMA data are presented in Figure 6 for latex with the different crosslinking functionalities obtained from films that were formed immediately after the crosslinker addition. Taking $80^{\circ} \mathrm{C}$ as a temperature at which to compare the $E^{\prime}$ values, because it is well above the $T_{\mathrm{g}}$ region, the effects of crosslinks are evident (Figure 6a). The values of $E^{\prime}$ at $80{ }^{\circ} \mathrm{C}$ decrease in order as $14>13>15>3$ (see Table 3). As expected, the polymer without crosslinks (Latex 3) has the lowest $E^{\prime}$, whereas $E^{\prime}$ is higher in the crosslinked films. Values of $E^{\prime}$ at room temperature $\left(20^{\circ} \mathrm{C}\right)$, nearer to the glass transition region, are shown for comparison in Table 3. In the $\tan \delta$ curves presented in Figure 6b, it can be seen in the high temperature region above the glass transitions that Latex 13 is the least dissipative of the four compositions. This is because its internal crosslinks are the most effective in restricting long-range chain motion and imparting elasticity. In the other extreme, Latex 3 has the highest $\tan \delta$ values and is the most dissipative, because it lacks crosslinks.

Analysis of the peaks in the E', curves (Figure S6) shows two transitions for each latex (Table 3) which are interpreted as glass transitions (as also found with DSC analysis). There is an upper $T_{\mathrm{g}}$ for Latex 15 at $14.7^{\circ} \mathrm{C}$. This is higher than the upper $T_{\mathrm{g}}$ for Latex 14 , which is at 5.7 ${ }^{\circ} \mathrm{C}$. Latex 13 has the lowest $T_{\mathrm{g}}\left(3.5^{\circ} \mathrm{C}\right)$ according to $E$ '” analysis. These values are consistent with the observation of film formation at room temperature.

The coalescence of particles requires the viscoelastic deformation of particles to fill the available volume. ${ }^{58}$ Without a sufficient viscous component, the voids at the particle boundaries will never be fully closed. Similarly, the flattening of particles at the film surface requires viscous flow. To interpret our microscopy results, it is therefore relevant to consider the loss modulus, $E^{\prime \prime}$ as an indicator of the ability of a polymer to flow. The viscosity of the polymer is related to $E$ ' ' through the strain frequency. Values of $E$ ', at $20{ }^{\circ} \mathrm{C}$ are listed in 


\section{Table 3.}

The value of $E$ ', for Latex 15 is higher than Latex 14, which offers a partial explanation why the particle flattening and coalescence is less for Latex 15. The lowest $E$ '’ is found for Latex 13 (internally crosslinked with BuDA). This result suggests that even though the chains are mobile on short length scales, the crosslinks within the particles restrict the particle deformation and flattening, which require flow over large length scales. Furthermore, our results underscore the importance of interdiffusion preceding crosslinking. Although Latex 13 has a high gel content and a high storage modulus in the rubbery region, it is the most brittle under high strains and exhibits incomplete particle coalescence.

(a)

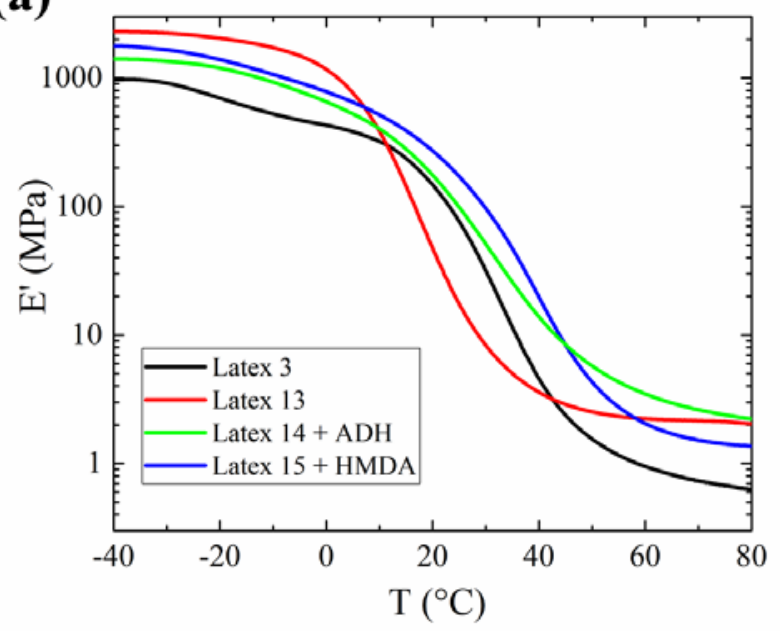

(b)

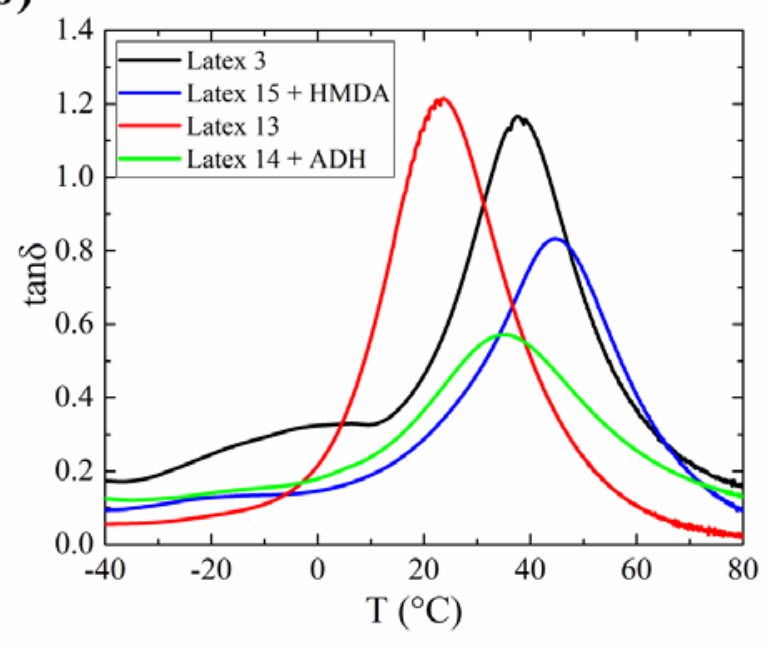


Figure 6. DMA curves for the different latex films investigated: (a) Storage modulus and (b) $\tan \delta$ (See Tables 1 and 2 for more information on these samples).

\section{CONCLUSIONS}

The concepts of polymerization-induced self-assembly were advantageously used in the present paper for the surfactant-free synthesis of film-forming latexes. The minimum amount of PMAA macroRAFT agent was used to mediate the polymerization of mixtures of MMA, BA and S. Employing from 1.5 wt.\% down to 0.75 wt.\% of macroRAFT agent, emulsion polymerizations were conducted to very high conversion (>93\%) with very low amounts of coagulum (less than 0.5 wt.\%) and achieving particle sizes in the 100-200 nm range. Only traces of residual macroRAFT agent could be detected in the final latexes showing that most of them have been chain extended to form amphiphilic block copolymers ensuring the stability of the latexes. The $T_{g}$ of the final material can be adjusted by the composition of the hydrophobic monomer mixtures according to a batch or a semi-batch process. Film-forming latex particles were obtained. Additional conventional crosslinking strategies using hydrophobic co-monomers such as BuDA, DAAm or AAEM were successfully applied to these formulations as attested by very high gel fractions.

Evaluation of films shows that the DAAm strategy, when used together with an ADH external crosslinker, provides the preferred mechanical properties: high modulus and strength combined with a high strain at failure. In this system, the coalescence occurs at a sufficient rate to be complete before crosslinking restricts chain motion. In contrast, the internal crosslinking of the latex particles with BuDA raises the storage modulus of the samples, but films are brittle and fail at very low strains, because the crosslinks inhibit particle deformation and restrict chain diffusion across particle boundaries. There is a lack of coalescence and 
weak particle boundaries in the internally cross-linked latex films. The barrier properties of these surfactant-free films will be reported in a future publication.

The knowledge platform gained in this study may broaden the scope of waterborne polymer colloids for innovative applications in coatings, inks, encapsulants, and adhesives plus more generally where free surfactant molecules can have a deleterious effect and/or crosslinking is required.

\section{Acknowledgments}

This work was funded by the European Union Seventh Framework Programme BARRIERPLUS project (FP7-SME-2012-2, No. 304758). We thank Pierre-Yves Dugas (C2P2) for cryo-TEM analyses, Manel Taam (C2P2) and Franck Collas (Mettler Toledo) for DSC measurements and Violeta Doukova (Surrey) for general laboratory support. We benefited from useful discussions with Richard Sear, Andrea Fortini (Surrey), and Claire Boncompain (Paint Research Association).

Supporting Information. Analytical techniques (NMR, viscosity measurements, size exclusion chromatography, dynamic light scattering, tensiometry, differential scanning calorimetry and $\mathrm{pH}$ measurement). Properties of some surfactant-free latexes prepared in the presence of PMAA $2 k$ macroRAFT agent; DSC curves of Latex 2, Latex 3 and Latex 4; Kinetics of the emulsion polymerizations of Latex 2, Latex 3, Latex 10 and Latex 12; Size exclusion chromatograms of PMAA $_{2 \mathrm{k}}$, Latex 2, Latex 3, Latex 10 and Latex 12; Surface tension measurements for Latex 3, compared to that of water and various concentrations of aqueous solutions of the macroRAFT agent $\mathrm{PMAA}_{2 \mathrm{k}}$; Visual stability test of Latex 3 at $50{ }^{\circ} \mathrm{C}$; Properties of the surfactant-free and (self-)crosslinking latexes prepared in the presence of $1 \mathrm{wt} \%$ of PMAA $2 \mathrm{k}$ macroRAFT agent; Stress/strain analysis for Latex 14 and 15 films cast immediately after adding crosslinker 
(ADH or HMDA) and after 21 days of aging; Loss modulus ( $E$ '’) for Latex 3, Latex 13, Latex $14(+\mathrm{ADH})$ and Latex 15 (+HMDA).

\section{References}

1. Directive 2004/42/CE of the European Parliament and of the Council of 21 April 2004 on the limitation of emissions of volatile organic compounds due to the use of organic solvents in certain paints and varnishes and vehicle refinishing products and amending Directive 1999/13/EC. In EUR-Lex - 32004L0042, 2004.

2. Gromer, A.; Thalmann, F.; Hébraud, P.; Holl, Y., Simulation of Vertical Surfactant Distributions in Drying Latex Films. Langmuir 2017, 33 (2), 561-572.

3. Heldmann, C.; Cabrera, R. I.; Momper, B.; Kuropka, R.; Zimmerschied, K., Influence of non-ionic emulsifiers on the properties of vinyl acetate/VeoVa10 and vinyl acetate/ethylene emulsions and paints Prog. Org. Coat. 1999, 35, 69-77.

4. Butler, L. N.; Fellows, C. M.; Gilbert, R. G., Effect of surfactant systems on the water sensitivity of latex films. J. Appl. Polym. Sci. 2004, 92 (3), 1813-1823.

5. Shouldice, G. T. D.; Vandezande, G. A.; Rudin, A., Practical aspects of the emulsifierfree emulsion polymerization of styrene. Eur. Polym. J. 1994, 30 (2), 179-183.

6. Chen, Y.; Zhang, C.; Chen, X., Emulsifier-free latex of fluorinated acrylate copolymer. Eur. Polym. J. 2006, 42 (3), 694-701.

7. Cui, X.; Zhong, S.; Gao, Y.; Wang, H., Preparation and characterization of emulsifierfree core-shell interpenetrating polymer network-fluorinated polyacrylate latex particles. Colloids Surf. A 2008, 324 (1-3), 14-21. 
8. Soer, W. J.; Ming, W.; Klumperman, B.; Koning, C.; van Benthem, R., Surfactant-free artificial latexes from modified styrene-maleic anhydride (SMA) copolymers. Polymer 2006, 47 (22), 7621-7627.

9. Schlarb, B.; Rau, M. G.; Haremza, S., Hydroresin dispersions: new emulsifier free binders for aqueous coatings. Prog. Org. Coat. 1995, 26 (2), 207-215.

10. Liu, Y.; Soer, W.-J.; Scheerder, J.; Satgurunathan, G.; Keddie, J. L., Water Vapor Sorption and Diffusion in Secondary Dispersion Barrier Coatings: A Critical Comparison with Emulsion Polymers. ACS Appl. Mater. Interfaces 2015, 7 (22), 12147-12157.

11. Bilgin, S.; Tomovska, R.; Asua, J. M., Effect of ionic monomer concentration on latex and film properties for surfactant-free high solids content polymer dispersions. Eur. Polym. J. 2017, 93, 480-494.

12. Charleux, B.; Delaittre, G.; Rieger, J.; D'Agosto, F., Polymerization-induced selfassembly: from soluble macromolecules to block copolymer nano-objects in one step. Macromolecules 2012, 45 (17), 6753-6765.

13. Lansalot, M.; Rieger, J.; D'Agosto, F., Polymerization-Induced Self-Assembly: The Contribution of Controlled Radical Polymerization to The Formation of Self-Stabilized Polymer Particles of Various Morphologies. In Macromolecular Self-assembly, John Wiley \& Sons, Inc.: 2016; pp 33-82.

14. Canning, S. L.; Smith, G. N.; Armes, S. P., A Critical Appraisal of RAFT-Mediated Polymerization-Induced Self-Assembly. Macromolecules 2016, 49 (6), 1985-2001.

15. Derry, M. J.; Fielding, L. A.; Armes, S. P., Polymerization-induced self-assembly of block copolymer nanoparticles via RAFT non-aqueous dispersion polymerization. Prog. Polym. Sci. 2016, 52, 1-18. 
16. Delaittre, G.; Nicolas, J.; Lefay, C.; Save, M.; Charleux, B., Surfactant-free synthesis of amphiphilic diblock copolymer nanoparticles via nitroxide-mediated emulsion polymerization. Chem. Commun. 2005, (5), 614-616.

17. Ferguson, C. J.; Hughes, R. J.; Pham, B. T. T.; Hawkett, B. S.; Gilbert, R. G.; Serelis, A. K.; Such, C. H., Effective ab Initio Emulsion Polymerization under RAFT Control. Macromolecules 2002, 35 (25), 9243-9245.

18. Okubo, M.; Sugihara, Y.; Kitayama, Y.; Kagawa, Y.; Minami, H., Emulsifier-Free, Organotellurium-Mediated Living Radical Emulsion Polymerization of Butyl Acrylate. Macromolecules 2009, 42 (6), 1979-1984.

19. Rieger, J., Guidelines for the Synthesis of Block Copolymer Particles of Various Morphologies by RAFT Dispersion Polymerization. Macromol. Rapid Commun. 2015, 36 (16), 1458-1471.

20. Warren, N. J.; Armes, S. P., Polymerization-Induced Self-Assembly of Block Copolymer Nano-objects via RAFT Aqueous Dispersion Polymerization. J. Am. Chem. Soc. 2014, 136 (29), 10174-10185.

21. Zhang, W.; D'Agosto, F.; Boyron, O.; Rieger, J.; Charleux, B., Toward Better Understanding of the Parameters that Lead to the Formation of Nonspherical Polystyrene Particles via RAFT-Mediated One-Pot Aqueous Emulsion Polymerization. Macromolecules 2012, 45 (10), 4075-4084.

22. Zhang, W.; D'Agosto, F.; Dugas, P.-Y.; Rieger, J.; Charleux, B., RAFT-mediated onepot aqueous emulsion polymerization of methyl methacrylate in presence of poly(methacrylic acid-co-poly(ethylene oxide) methacrylate) trithiocarbonate macromolecular chain transfer agent. Polymer 2013, 54 (8), 2011-2019. 
23. Lesage de la Haye, J.; Zhang, X.; Chaduc, I.; Brunel, F.; Lansalot, M.; D'Agosto, F., The Effect of Hydrophile Topology in RAFT-Mediated Polymerization-Induced SelfAssembly. Angew. Chem. Int. Ed. 2016, 55 (11), 3739-3743.

24. Chaduc, I.; Reynaud, E.; Dumas, L.; Albertin, L.; D'Agosto, F.; Lansalot, M., From well-defined poly(N-acryloylmorpholine)-stabilized nanospheres to uniform mannuronanand guluronan-decorated nanoparticles by RAFT polymerization-induced self-assembly. Polymer 2016, 106, 218-228.

25. Chenal, M.; Rieger, J.; Véchambre, C.; Chenal, J.-M.; Chazeau, L.; Creton, C.; Bouteiller, L., Soft Nanostructured Films with an Ultra-Low Volume Fraction of Percolating Hard Phase. Macromol. Rapid Commun. 2013, 34 (19), 1524-1529.

26. Chenal, M.; Véchambre, C.; Chenal, J.-M.; Chazeau, L.; Humblot, V.; Bouteiller, L.; Creton, C.; Rieger, J., Mechanical properties of nanostructured films with an ultralow volume fraction of hard phase. Polymer 2017, 109, 187-196.

27. Albiges, R.; Klein, P.; Roi, S.; Stoffelbach, F.; Creton, C.; Bouteiller, L.; Rieger, J., Water-based acrylic coatings reinforced by PISA-derived fibres. Polym. Chem. 2017, 8, 49924995.

28. Li, F.; Schellekens, M.; de Bont, J.; Peters, R.; Overbeek, A.; Leermakers, F. A. M.; Tuinier, R., Self-Assembled Structures of PMAA-PMMA Block Copolymers: Synthesis, Characterization, and Self-Consistent Field Computations. Macromolecules 2015, 48 (4), 1194-1203.

29. dos Santos, A. M.; Pohn, J.; Lansalot, M.; D'Agosto, F., Combining steric and electrostatic stabilization using hydrophilic MacroRAFT agents in an Ab initio emulsion polymerization of styrene. Macromol. Rapid Commun. 2007, 28 (12), 1325-1332.

30. Bathfield, M.; D'Agosto, F.; Spitz, R.; Charreyre, M.-T.; Pichot, C.; Delair, T., Submicrometer sized hairy latex particles synthesized by dispersion polymerization using 
hydrophilic macromolecular RAFT agents. Macromol. Rapid Commun. 2007, 28 (15), 15401545.

31. Manguian, M.; Save, M.; Charleux, B., Batch Emulsion Polymerization of Styrene Stabilized by a Hydrophilic Macro-RAFT Agent. Macromol. Rapid Commun. 2006, 27 (6), 399-404.

32. Tichagwa, L.; Götz, C.; Tonge, M.; Sanderson, R.; Pash, H., The Use of Selected Acrylate and Acrylamide-Based Surfmers and Polysoaps in the Emulsion Polymerization of Styrene. Macromol. Symp. 2003, 193 (1), 251-260.

33. Velasquez, E.; Rieger, J.; Stoffelbach, F.; D'Agosto, F.; Lansalot, M.; Dufils, P.-E.; Vinas, J., Surfactant-free poly(vinylidene chloride) latexes via one-pot RAFT-mediated aqueous polymerization. Polymer 2016, 106, 275-284.

34. Colby, R. H.; Rubinstein, M., In Polymer Physics, Press, O. U., Ed. Oxford, 2009.

35. Zosel, A.; Ley, G., Influence of crosslinking on structure, mechanical properties, and strength of latex films. Macromolecules 1993, 26 (9), 2222-2227.

36. Taylor, J. W.; Winnik, M. A., Functional latex and thermoset latex films. J. Coat. Technol. Res. 2004, 1 (3), 163-190.

37. Keddie, J. L.; Routh, A. F., Fundamentals of Latex Film Formation: Processes and Properties. Springer Dordecht Netherlands: 2010.

38. Aradian, A.; Raphaeel, E.; de Gennes, P. G., Strengthening of a Polymer Interface: Interdiffusion and Cross-Linking. Macromolecules 2000, 33 (25), 9444-9451.

39. Tronc, F.; Chen, W.; Winnik, M. A.; Eckersley, S. T.; Rose, G. D.; Weishuhn, J. M.; Meunier, D. M., Epoxy-functionalized, low-glass-transition-temperature latex. II. Interdiffusion versus crosslinking in the presence of a diamine. J. Polym. Sci. Part A. Polym. Chem. 2002, 40 (22), 4098-4116. 
40. Boursier, T.; Chaduc, I.; Rieger, J.; D'Agosto, F.; Lansalot, M.; Charleux, B., Controlled radical polymerization of styrene in miniemulsion mediated by PEO-based trithiocarbonate macromolecular RAFT agents. Polym. Chem. 2011, 2 (2), 355-362.

41. Xu, X.; Smith, A. E.; Kirkland, S. E.; McCormick, C. L., Aqueous RAFT Synthesis of pH-Responsive Triblock Copolymer mPEO-PAPMA-PDPAEMA and Formation of Shell Cross-Linked Micelles. Macromolecules 2008, 41 (22), 8429-8435.

42. Chaduc, I.; Girod, M.; Antoine, R.; Charleux, B.; D'Agosto, F.; Lansalot, M., Batch Emulsion Polymerization Mediated by Poly(methacrylic acid) MacroRAFT Agents: One-Pot Synthesis of Self-Stabilized Particles. Macromolecules 2012, 45 (15), 5881-5893.

43. Chaduc, I.; Lansalot, M.; D'Agosto, F.; Charleux, B., RAFT Polymerization of Methacrylic Acid in Water. Macromolecules 2012, 45 (3), 1241-1247.

44. Kessel, N.; Illsley, D. R.; Keddie, J. L., The diacetone acrylamide crosslinking reaction and its influence on the film formation of an acrylic latex. J. Coat. Tech. Res. 2008, 5, 285-297.

45. Chaduc, I.; Crepet, A.; Boyron, O.; Charleux, B.; D'Agosto, F.; Lansalot, M., Effect of the $\mathrm{pH}$ on the RAFT Polymerization of Acrylic Acid in Water. Application to the Synthesis of Poly(acrylic acid)-Stabilized Polystyrene Particles by RAFT Emulsion Polymerization. Macromolecules 2013, 46 (15), 6013-6023.

46. Buback, M.; Feldermann, A.; Barner-Kowollik, C.; Lacík, I., Propagation Rate Coefficients of Acrylate-Methacrylate Free-Radical Bulk Copolymerizations. Macromolecules 2001, 34 (16), 5439-5448.

47. Ballard, M. J.; Gilbert, R. G.; Napper, D. H.; Pomery , P. J.; O’Donnell, J. H., The application of electron spin resonance spectroscopy to emulsion polymerization. EPR. Macromolecules 1984, 17, 504-506. 
48. Capek, I.; Barton, J.; Ordinova, E., Emulsion polymerization of butyl acrylate. Chem. Zvesti 1984, 38 (6), 803-822.

49. Jung, H. M.; Yoo, Y.; Kim, Y. S.; Lee, J. H., Microwave-Irradiated Copolymerization of Styrene and Butyl Acrylate. Macromol. Symp. 2007, 249-250 (1), 521-528.

50. Cruz, E. M. A.; Palacios, A. J.; García, R. A.; Ruiz, F. L. M.; Rios, G. L., Copolymérisation en émulsion styrène-acrylate de butyle en réacteur fermé. Makromol. Chem. 1985, 10 (10-11), 87-103.

51. Zhang, W.; D'Agosto, F.; Boyron, O.; Rieger, J.; Charleux, B., One-Pot Synthesis of Poly(methacrylic acid-co-poly(ethylene oxide) methyl ether methacrylate)-b-polystyrene Amphiphilic Block Copolymers and Their Self-Assemblies in Water via RAFT-Mediated Radical Emulsion Polymerization. A Kinetic Study. Macromolecules 2011, 44 (19), 75847593.

52. Rieger, J.; Osterwinter, G.; Bui, C.; Stoffelbach, F.; Charleux, B., Surfactant-Free Controlled/Living Radical Emulsion (Co)polymerization of n-Butyl Acrylate and Methyl Methacrylate via RAFT Using Amphiphilic Poly(ethylene oxide)-Based Trithiocarbonate Chain Transfer Agents. Macromolecules 2009, 42 (15), 5518-5525.

53. Chong, Y. K.; Krstina, J.; Le, T. P. T.; Moad, G.; Postma, A.; Rizzardo, E.; Thang, S. H., Thiocarbonylthio Compounds $[\mathrm{S}: \mathrm{C}(\mathrm{Ph}) \mathrm{S}-\mathrm{R}]$ in Free Radical Polymerization with Reversible Addition-Fragmentation Chain Transfer (RAFT Polymerization). Role of the FreeRadical Leaving Group (R). Macromolecules 2003, 36 (7), 2256-2272.

54. Lane, W. H., Determination of Solubility of Styrene in Water and of Water in Styrene. Ind. Eng. Chem. Anal. Ed. 1946, 18 (5), 295-296.

55. Ballard, M. J.; Napper, D. H.; Gilbert, R. G., MMA: Kinetics of emulsion polymerization of methyl methacrylate. J. Polym. Sci., Polym. Chem. Edn. 1984, 22 (11), 3225-3253. 
56. Kubo, K.; Goto, A.; Sato, K.; Kwak, Y.; Fukuda, T., Kinetic study on reversible addition-fragmentation chain transfer (RAFT) process for block and random copolymerizations of styrene and methyl methacrylate. Polymer 2005, 46 (23), 9762-9768.

57. Perez, E.; Lang, J., Flattening of latex film surface: Theory and experiments by atomic force microscopy. Macromolecules 1999, 32 (5), 1626-36.

58. Crowley, T. L.; Sanderson, A. R.; Morrison, J. D.; Barry, M. D.; Morton-Jones, A. J.; Rennie, A. R., Formation of bilayers and Plateau borders during the drying of film-forming latexes as investigated by small-angle neutron scattering. Langmuir 1992, 8 (9), 2110-2123. 


\section{For Table of Contents use only}

Hydrophilic MacroRAFT-Mediated Emulsion Polymerization: Synthesis of Latexes for

\section{Crosslinked and Surfactant-Free Films}

Jennifer Lesage de la Haye, ${ }^{1}$ Ignacio Martin-Fabiani, ${ }^{2}$ Malin Schulz, ${ }^{3}$ Joseph L. Keddie, ${ }^{3 *}$ Franck D’Agosto, ${ }^{1^{*}}$ Muriel Lansalot ${ }^{1^{*}}$

${ }^{1}$ Univ Lyon, Université Claude Bernard Lyon 1, CPE Lyon, CNRS, UMR 5265, Chemistry, Catalysis, Polymers \& Processes (C2P2), 43 Bd du 11 Novembre 1918, 69616 Villeurbanne, France.

${ }^{2}$ Department of Materials, Loughborough University, Loughborough, Leicestershire LE11 3TU, United Kingdom.

${ }^{3}$ Department of Physics, University of Surrey, Guildford, Surrey GU2 7XH, United Kingdom.

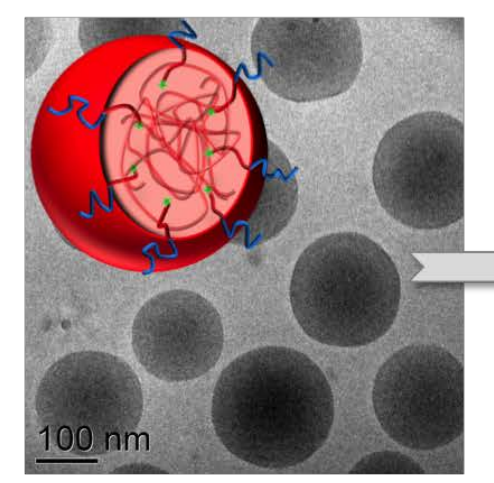

MacroRAFT-mediated emulsion polymerization
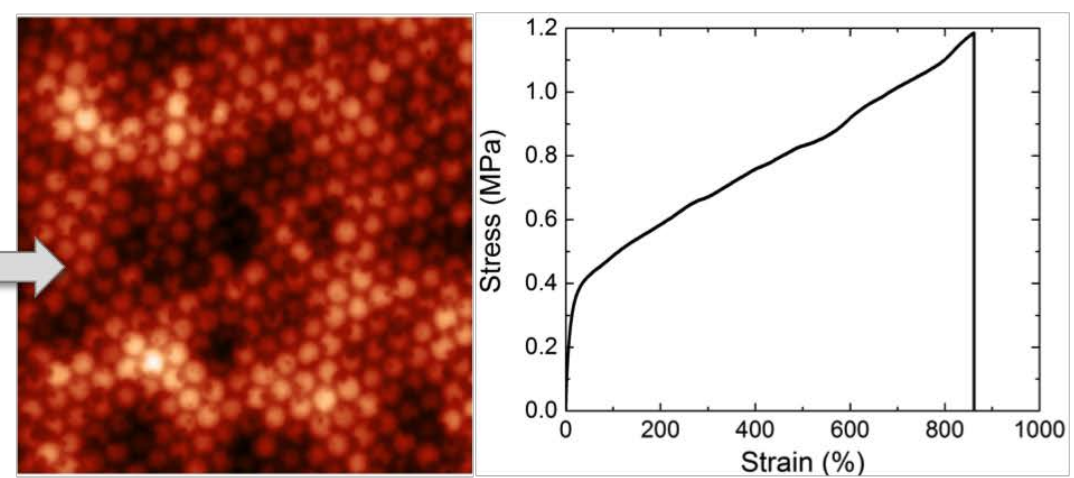

Crosslinked and surfactant-free films 